\title{
Linear and circular helicates: A brief review
}

\author{
ARUNA PRIYADARSINI PANEERSELVAM, SRABANI SROTOSWINI MISHRA and \\ DILLIP KUMAR CHAND*(D) \\ Department of Chemistry, Indian Institute of Technology Madras, Chennai, Tamilnadu 600 036, India \\ E-mail: dillip@iitm.ac.in; dillipiitm@gmail.com
}

MS received 20 March 2018; revised 19 May 2018; accepted 25 May 2018; published online 12 July 2018

\begin{abstract}
Helical self-assembled coordination complexes are broadly classified under linear and circular helicates. While the number of strands of the ligand units in a molecule of the linear helicates is used for further classifications such as single-stranded, double-stranded and so on, the circular helicates are not classified further. The compositions of helicates are considered as $\mathrm{M}_{x} \mathrm{~L}_{y}$ where the terms $x$ and $y$ stand for the number of metal ion(s) and ligand strands, respectively. However, more than one type of metal centers/ligand in helicates are also known. The linear helicates of a given number of strands are further classified under the number of metal centers such as binuclear, trinuclear and so on. Representative examples are included to exemplify the varieties of helicates.
\end{abstract}

Keywords. Self-assembly; Helicates; Ligand Strands; Metal centers.

\section{Introduction}

Self-assembled coordination complexes with particular reference to helicates ${ }^{1}$ are quite interesting in view of their unique architectures. In 1987, Nobel laureate J. -M. Lehn introduced the term 'helicate' for helical metal complexes. ${ }^{\text {a }}$ Piguet et al., for the first time, in the year 1997, brought the helicates into the limelight through a review article. ${ }^{1 \mathrm{~b}}$ One or more ligand strands and two or more metal centers are the usual components of a helicate. Helicates of $\mathrm{M}_{x} \mathrm{~L}_{y}$ compositions could be classified in terms of the number of metal ions and also the number of strands wrapped around metal centers in a given molecule (single or multiple stranded) and they vary in pitch (the distance along the helical axis for the strands to complete a full turn). The helicates are often characterized by analysing the corresponding single crystal structures of the title compounds where both enantiomers usually coexist in the crystal. Typical linear helicates $(\mathbf{1}-\mathbf{4})^{2}$ are shown in Figure 1 where one of the enantiomers is presented.

The metal centers of the $\mathrm{M}_{x} \mathrm{~L}_{y}$-type helicates are varied and represented by elements of all the series i.e., $s, p$, $d$ and $f$ block ( $x$ ranges usually from 1 to 6 ), whereas

\footnotetext{
*For correspondence
}

ligands, though varied, mostly pyridine-appended ligands are utilized (y ranges usually from 1 to 4 and 6). ${ }^{3}$ In some cases ancillary ligands or counter anions are ligated to complete the coordination sphere. Circular helicates can be considered as a special family of helicates and these are comparatively limited in number. ${ }^{1 \mathrm{~d}, 1 \mathrm{f}, 1 \mathrm{~g}}$ In general if a helix is viewed down its helical axis, the wrapping direction of the ligand strands appears clockwise or anticlockwise. The wrapping direction in a right-handed or $P$ (plus) helix is clockwise whereas for a left-handed or $M$ (minus) helicate it is anticlockwise. $^{4}$

For binuclear helicates, the configuration at both of the chirogenic metal center can be used to name the left-handed, right-handed and meso-helicates with the terms $M M, P P$ and $M P$ (i.e., $\Lambda \Lambda, \Delta \Delta$ and $\Lambda \Delta$ ), respectively (Figure 2). ${ }^{1 \mathrm{~d}}$ For binuclear helicates comprising of non-chirogenic metal centers, the direction of ligand wrapping between the two metal centers, around the imaginary central axis, is considered for naming the left and right-handed helicates with the terms $M$ and $P$ (i.e. $\Lambda, \Delta$ ), respectively ${ }^{1 \mathrm{~g}}$ (Figure 2). It is assumed that all the ligands are wrapped in the same direction and hence only one alphabet is enough to define an enantiomer.

Piguet et al., reviewed and classified a large variety of helicates on the basis of number of ligand strands and metal ions present in their architectures. ${ }^{1 \mathrm{~b}} \mathrm{~A}$ few 


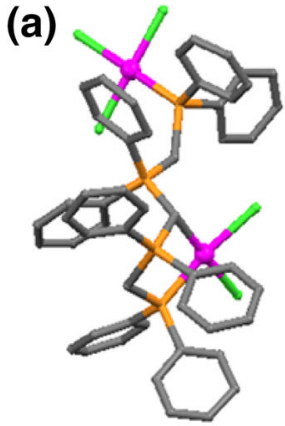

$\left[\mathrm{Pd}_{2}(\mathbf{L} \mathbf{1}) \mathrm{Cl}_{5}\right], 1$ (b)

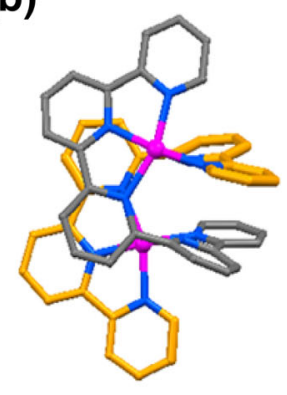

$\left[\mathrm{Pd}_{2}(\mathbf{L} 2)_{2}\right]\left(\mathrm{PF}_{6}\right)_{4}, 2$ (c)

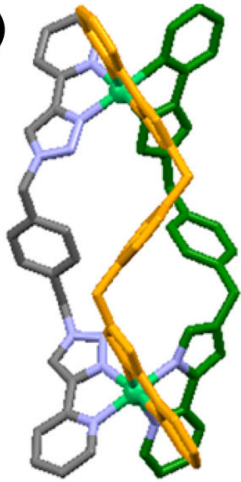

$\left[\mathrm{Ni}_{2}(\mathrm{~L} 3)_{2}\right]\left(\mathrm{BF}_{4}\right)_{4}, 3$ (d)

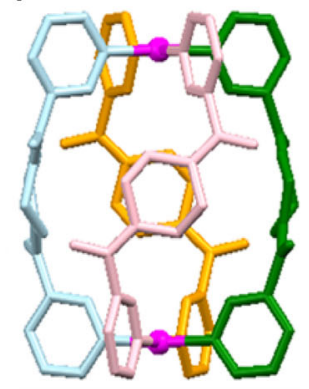

$\left[\mathrm{Pd}_{2}(\mathrm{L4})_{2}\right]\left(\mathrm{NO}_{3}\right)_{4}, 4$

Figure 1. Crystal structures of (1-4) showing one enantiomer of certain binuclear helicates: (a) single-stranded ${ }^{2 \mathrm{a}}$; (b) double stranded ${ }^{2 \mathrm{~b}}$; (c) triple-stranded ${ }^{2 \mathrm{c}}$; and (d) quadruple-stranded helicates $^{2 \mathrm{~d}}$ (non-coordinating anions, $\mathrm{H}$ and solvents are excluded).

(a)

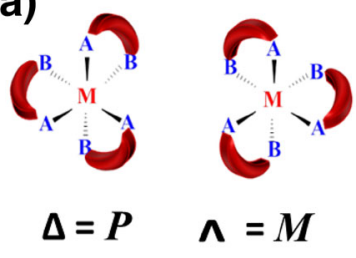

(b)

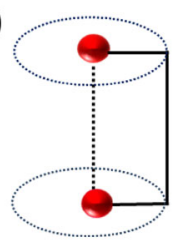

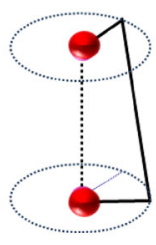

$\boldsymbol{P}$

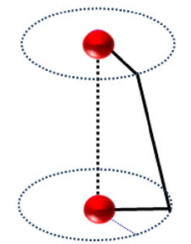

M

Figure 2. Cartoon diagrams showing (a) possible absolute configurations of chirogenic metal centers of a helicate; ${ }^{1 \mathrm{~b}}$ (b) handedness of ligand bound to non-chirogenic metal center. $2 \mathrm{e}$

years later, Albrecht reviewed helicates ${ }^{1 \mathrm{~d}}$ with updated literature by adding further classifications based on the kind of donor ligands present in the helicates. Later on, some other groups also reviewed helicates, ${ }^{1 \mathrm{e}-1 \mathrm{~g}}$ which discussed the new varieties and their emerging applications. ${ }^{1 \mathrm{f}}$ The most recent review in this area by Constable in the year 2013 included new examples. ${ }^{1 \mathrm{~g}}$ The purpose of the present review is to update the readers with further developments in the area of helicates with particular reference to the new varieties reported during the last few years along with some classical examples. The classification has been made on the basis of number of ligand strands in a helicate that has been further sub-divided into the nuclearity of the helicates such as binuclear, trinuclear and so on, as appropriate. To make the review short but still provide the varieties to the readers, only representative examples are shown.

\section{Variety of helicates}

An overview of linear helicates based on number of strands containing different metal centers is provided below. In very few cases, selective formation of only one enantiomer was found. Generally, in most of the helicates two isomers were found. However, only one of the isomer is shown for simplicity. Then the circular helicates are represented in the latter part of the review.

\subsection{Single-stranded helicates}

In single-stranded helicates, a single ligand strand wraps around the metal center/centers in a helical fashion. When considering the double-stranded helicates, the single-stranded helicates ${ }^{5-10}$ are few in number. Representative examples are discussed further.

Chiral $C_{2}$-symmetric quarterpyridine $\mathbf{L 5}$ reacts with $[\mathrm{Pd}$ $\left.\left(\eta^{3}-\mathrm{C}_{3} \mathrm{H}_{5}\right) \mathrm{Cl}\right]_{2}$ in presence of $\mathrm{AgSbF}_{6}$ salt to form $\left[\mathrm{Pd}_{2}\left(\eta^{3}-\right.\right.$ $\left.\left.\mathrm{C}_{3} \mathrm{H}_{5}\right)_{2}(\mathbf{L 5})\right]\left(\mathrm{SbF}_{6}\right)_{2}, 5$ a chiral single-stranded helicate. ${ }^{6}$ The crystal structure revealed the stereoselective formation of $M$-helix with $(R)$-isopinocampheol auxiliary (Figure 3 ). Further, the chiral helicate $\mathbf{5}$ was utilised as an efficient catalyst for enantioselective allylic substitution.

During the complexation of $\mathrm{Cu}(\mathrm{OAC})_{2}$ with the cyclic octapyrrolic helix, $\mathrm{H}_{4} \mathbf{L} \mathbf{6}^{\prime}$ that was carried out under bubbling oxygen, an interesting phenomenon of oxidative cleavage of the ligand occurred giving a binuclear complex of the cleaved ligand as one of the products. The formula of the singlestranded helicate is $\left[\mathrm{Cu}_{2}(\mathbf{L 6})\right]$ as shown in Figure $4 .{ }^{7}$ One of 

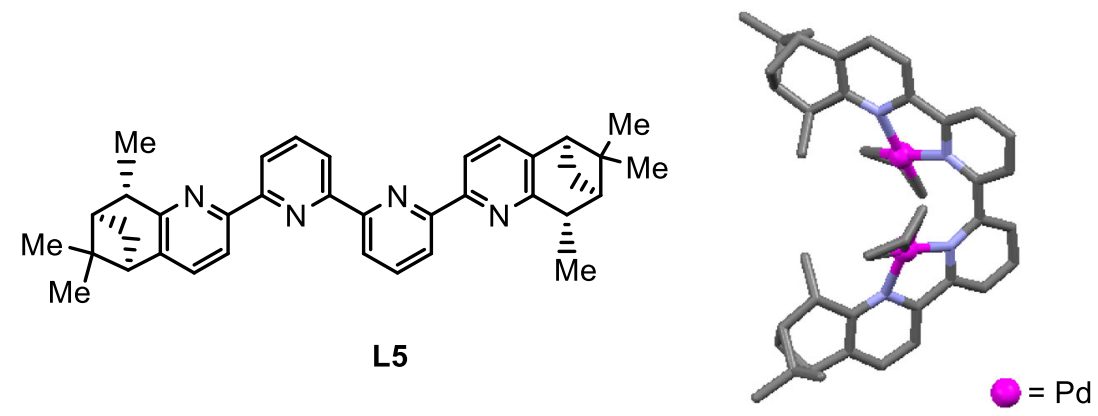

5

Figure 3. Ligand $\mathbf{L 5}$ and $\mathrm{X}$-ray structure of $\left[\mathrm{Pd}_{2}\left(\eta^{3}-\mathrm{C}_{3} \mathrm{H}_{5}\right)_{2}(\mathbf{L 5})\right]\left(\mathrm{SbF}_{6}\right)_{2}$, 5 showing a single-stranded helicate (Hydrogen atoms and non-coordinating anions are not shown for clarity).
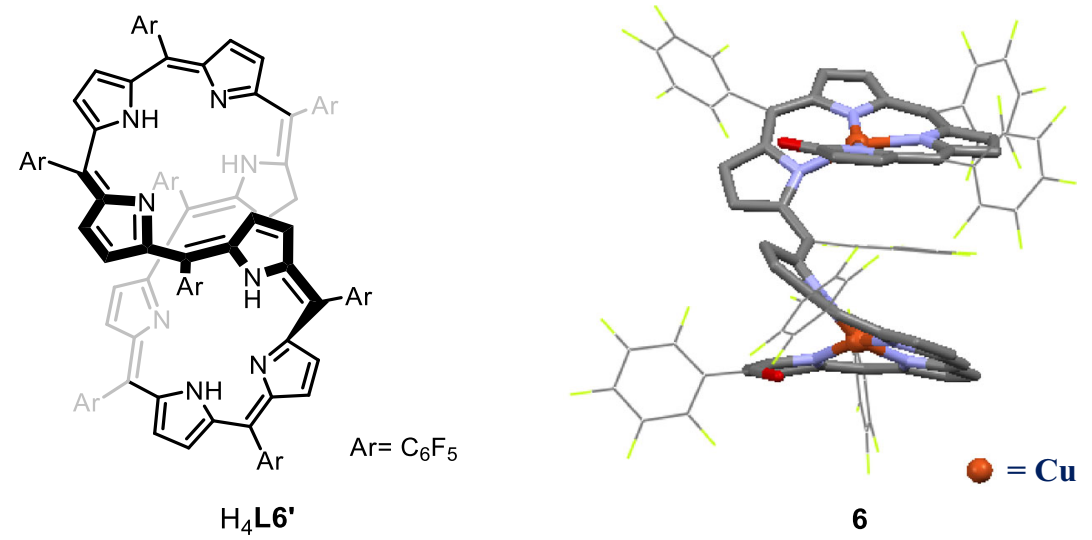

Figure 4. Ligand $\mathrm{H}_{4} \mathbf{L} \mathbf{6}^{\prime}$ and $\mathrm{X}$-ray structure of $\left[\mathrm{Cu}_{2}(\mathbf{L 6})\right], \mathbf{6}$ showing a single-stranded helicate (Hydrogen atoms and anions are not shown for clarity).

the meso-pentafluorophenyl substituents is inserted between the two turns of the helical backbone, causing a long $\mathrm{Cu}-\mathrm{Cu}$ distance of $6.28 \AA$ and an irregular helix pitch of 5-8.

A hexapyrrole- $\alpha$, $\omega$-dialdehyde, $\mathrm{H}_{4} \mathbf{L} 7$ with terminal aldehyde groups (for the introduction of chirality) was reacted with $\left[\mathrm{PdCl}_{2}(\mathrm{MeCN})_{2}\right]$ to give single-stranded helicate, $\left[\mathrm{Pd}_{2}\right.$ (L7) $], 7^{8}$ (Figure 5). The dipalladium(II) hexapyrroles was found to be dynamic and the rate of the conformational change was significantly slowed down by the conversion of the terminal formyl group into the imine group.

A tetranuclear single-stranded metallohelicate $\left[\mathrm{Zn}_{3} \mathrm{La}(\mathbf{L 8})\right.$ $\left.(\mathrm{OAc})_{3}\right],{ }^{9} \mathbf{8}$ was spontaneously formed by the complexation of zinc(II) and lanthanum(III) with a chiral salen ligand, $\mathrm{H}_{6} \mathbf{L 8}$ having a trans-1,2-diphenylethylene group. The preferential one-handed coiled structure was obtained due to the presence of chiral auxiliary unit in the ligand $\mathrm{H}_{6} \mathbf{L 8}$ (Figure 6).

The tetradentate bisacetylacetonato ligand, $\mathbf{L 9}$ forms a single-stranded binuclear helicate ${ }^{10}$ (Figure 7) with cisprotected palladium(II) unit i.e. $\mathrm{Pd}(\mathrm{bpy})\left(\mathrm{PF}_{6}\right)_{2}$. The nonbonded Pd ${ }^{\cdots} \mathrm{Pd}$ distance is $8.028 \AA$ A However, this can also be termed as twisted type complex.

\subsection{Double-stranded helicates}

Double-stranded helicates can be further subdivided into binuclear and trinuclear double-stranded metallohelicates. A few higher nuclear/ infinite double-stranded metallohelicates were also reported. ${ }^{11}$ Few representative examples of binuclear double-stranded metallohelicate ${ }^{12-20}$ containing metal ions like copper(II), cobalt(II), nickel(II), ruthenium(II), zinc(II), palladium(II), rhenium(I) are given below.

Khutia et al., reported a heterometallic double-stranded helicate, ${ }^{13} \mathbf{1 0}$ by the complexation of $\mathrm{Pd}(\mathrm{bpy})\left(\mathrm{NO}_{3}\right)_{2}$ with the neutral metallo-ligand, L10. The metallo-ligand L10 acted as a bridging ligand between the palladium(II) centers (Figure 8). Out of multiple possibilities, a single rotameric state is favoured, i.e., the head-to-tail arrangement of cytosinate ligand was found at the platinum corners. This is attributed to the presence of favorable inter-nucleobase hydrogen-bond formation and the absence of unfavourable repulsive interactions.

Hannon et al., has examined the secondary inter-strand interactions in a double-helical ${ }^{14}$ structure containing iminebased ligands, $\mathbf{L 1 1}$. The structure of the helicate $\left[\operatorname{Ag}_{2}(\mathbf{L 1 1})_{2}\right]$ 


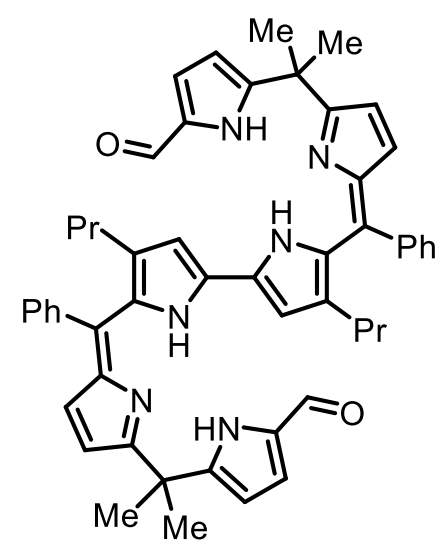

$\mathrm{H}_{4} \mathrm{L7}$

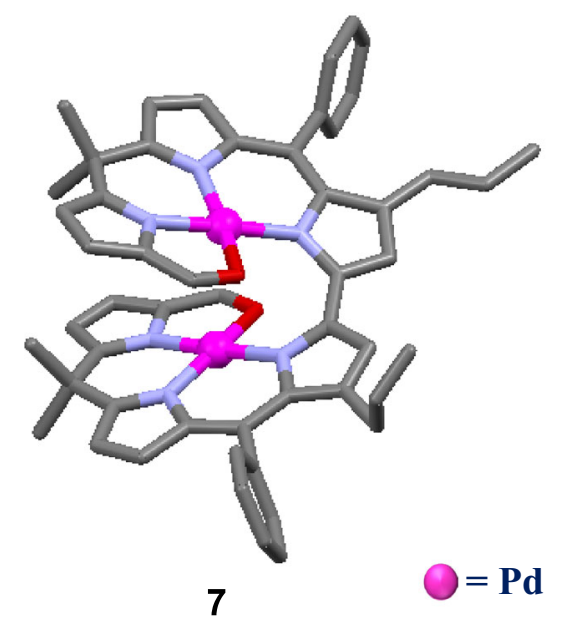

7

Figure 5. Ligand $\mathrm{H}_{4} \mathbf{L} 7$ and $\mathrm{X}$-ray structure of $\left[\mathrm{Pd}_{2}(\mathbf{L} \mathbf{2})\right]$, 7 showing a single-stranded helicate (Hydrogen atoms and non-coordinating anions are not shown for clarity).
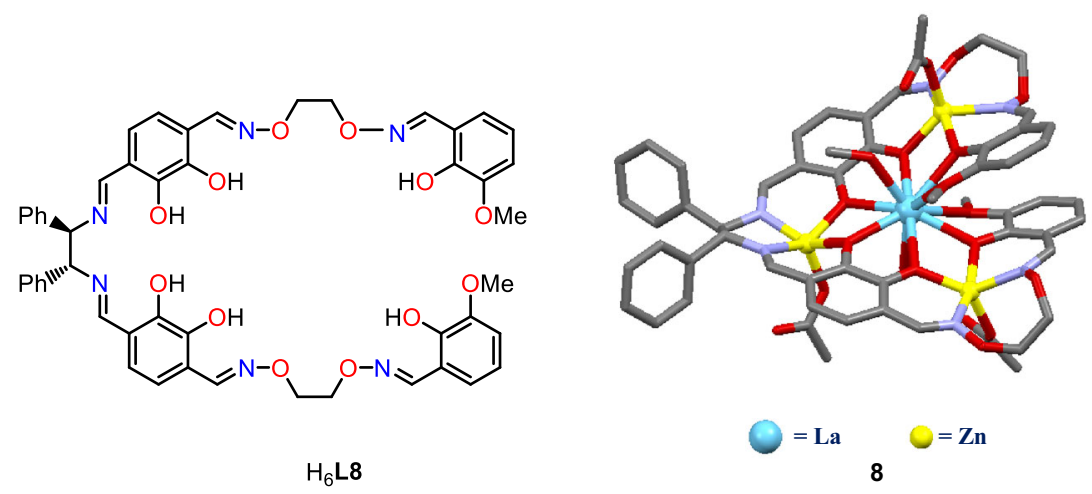

Figure 6. Ligand $\mathrm{H}_{6} \mathbf{L 8}$ and $\mathrm{X}$-ray structure of $\left[\mathrm{Zn}_{3} \mathrm{La}(\mathbf{L 8})(\mathrm{OAc})_{3}\right], \mathbf{8}$ a single-stranded tetranuclear metallohelicate bearing a chiral auxiliary (Hydrogen atoms and non-coordinating anions are not shown for clarity).

$\left(\mathrm{PF}_{6}\right)_{2}, 11$ was found to contain major and minor grooves reminiscent of B-DNA (Figure 9). The phenyl rings of the diarylmethane spacer of the ligands are face-edge $\pi$-stacked with each other. Hence, the two ligand strands are pulled together on one side of the helical axis which inevitably leads to the presence of two distinct helical grooves (major and minor).

Cooke et al., reported ligands L12, L13 forming either a dinuclear double helicate or mesocate depending on the size of the metal ion or the steric bulk of the ligand strand. ${ }^{15}$ The ligand $\mathbf{L 1 2}$ forms a dinuclear double helicate with cadmium(II) (Figure 10) but a dinuclear meso-helicate with both cobalt(II) and zinc(II). The difference is attributed to unfavorable steric interactions which prevent the formation of a helicate with the smaller cobalt(II) and zinc(II) ions. Further, the inclusion of sterically demanding groups on the ligand chain i.e., $\mathbf{L 1 3}$ results in a cadmium-containing meso-helicate. Solid-state structure of $\left[\mathrm{Fe}_{2}(\mathbf{L 1 2})_{2}\right]\left(\mathrm{ClO}_{4}\right)_{4}$ and $\left[\mathrm{Cd}_{2}(\mathbf{L 1 2})_{2}\right]\left(\mathrm{ClO}_{4}\right)_{4}$ complex cation was found to be helical. However, the inclusion of a sterically demanding group can force the formation of a meso-helicate as in the case of $\left[\mathrm{Cd}_{2}(\mathbf{L 1 3})_{2}\right]\left(\mathrm{ClO}_{4}\right)_{4}$.

A binuclear double-stranded palladium helicate, $\mathbf{1 4}^{16}$ was reported by Guchhiat et al., in 2015. The palladium complex $\left[\mathrm{Pd}_{2}(\mathbf{L 1 4})_{2} \mathrm{Cl}_{4}\right], 14$ was synthesized by treating dipyrrolylmethane based ditopic tecton, 1,9-bis(3,5dimethylpyrazolylmethyl)-dipyrrolylmethane, containing diethyl substituent at the meso carbon atom, L14 with $\left[\mathrm{Pd}(\mathrm{PhCN})_{2} \mathrm{Cl}_{2}\right]$ (Figure 11).

Telfer et al., reported the formation of dinuclear helicates ${ }^{17}$ with a novel, noncovalent strategy. Eight simple components (four metal ions and four ligand molecules) selfassemble to form a dinuclear double-stranded helicate and the resulting structure is stabilized by coordination bonds, hydrogen bonds and $\pi-\pi$ interactions (Figure 12). Here, the hydrogen bonding between simple pyridine-alcohol precursors build up the ligand backbone. The crystal structure of $\left[\mathrm{Co}(\mathrm{HL15})_{2} \mathrm{Cl}\right]\left[\mathrm{Co}(\mathbf{L 1 5})_{2} \mathrm{Cl}\right], \mathbf{1 5}$ reveals that a pair of 
<smiles>CC(=O)C(C(C)=O)=C(C(C)=O)C(C)=O</smiles>

L9

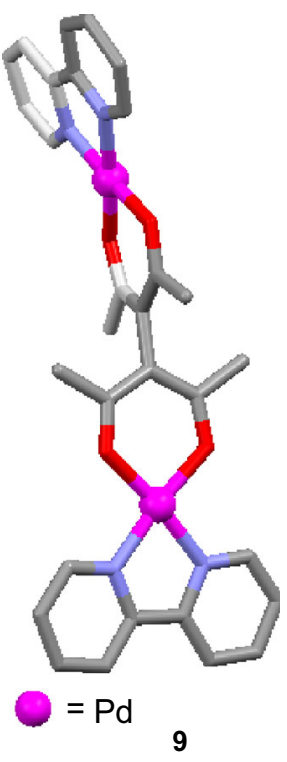

Figure 7. Ligand L9 and X-ray structure of $\left[\mathrm{Pd}_{2}(\mathrm{bpy})_{2}(\mathbf{L 9})\right]\left(\mathrm{PF}_{6}\right)_{2}, \mathbf{9}$ a single-stranded binuclear metallohelicate (Hydrogen atoms and non-coordinating anions are not shown for clarity).

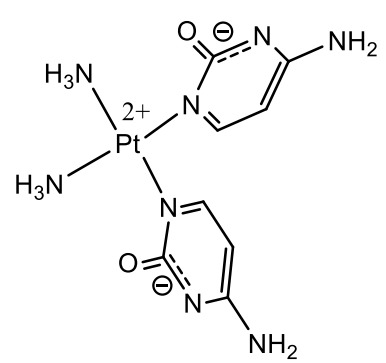

L10

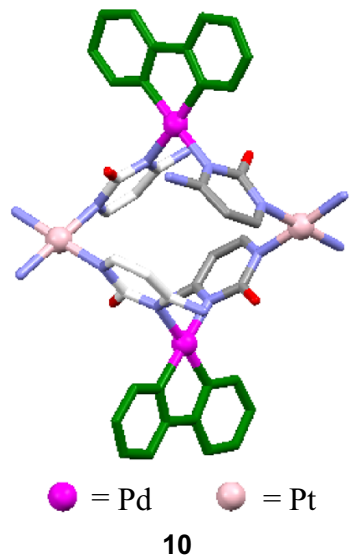

10
Figure 8. Ligand L10, crystal structure of $\left[\mathrm{Pd}_{2}(\text { bpy })_{2}(\mathbf{L 1 0})_{2}\right]\left(\mathrm{NO}_{3}\right)_{4}, \quad \mathbf{1 0}$ a tetranuclear double-stranded helicate (Hydrogen atoms and non-coordinating anions are not shown for clarity).

pyridine-methanol moieties are hydrogen-bonded via their oxygen atoms to form a bis-bidentate ligand strand (Figure 12). ${ }^{17}$ Two such strands wrap around an axis defined by two cobalt(II) ions to give a dinuclear double-stranded helicate. A chloride ion completes the coordination sphere of each metal center. Further, the helicates formed are highly stereoselective. Only homochiral ligand sets are observed and the chirality of these ligands efficiently predetermines the absolute configuration of the metal centers.

Katagiri et al., reported the crystal structure of a spiroborate-based trinuclear double-helicates $\mathrm{H}\left[\mathrm{B}_{2} \mathrm{Na}\right.$ $\left.\left(\mathrm{H}_{2} \mathbf{L 1 6}\right)_{2}\right], 16 .{ }^{18}$ The helicate consists of two boron atoms,
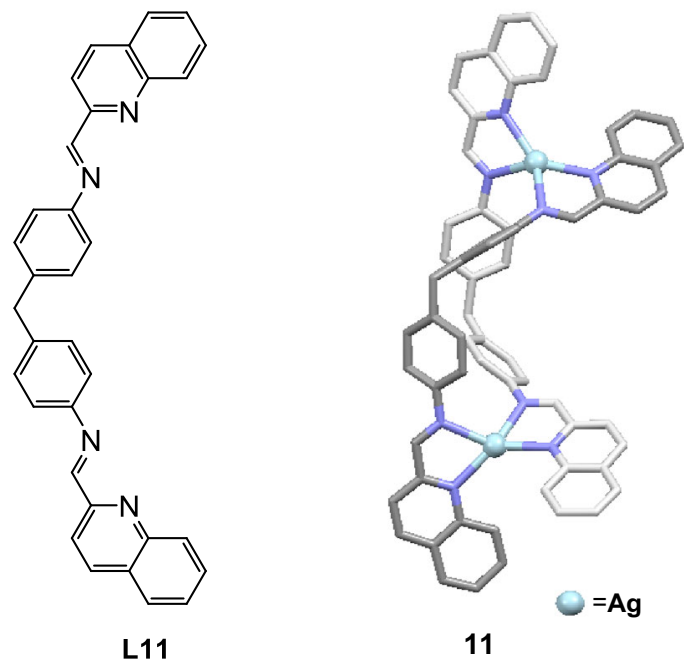

Figure 9. Ligand L11 and crystal structure of $\left[\mathrm{Ag}_{2}(\mathbf{L 1 1})_{2}\right]\left(\mathrm{PF}_{6}\right)_{2}, \mathbf{1 1}$, a binuclear double-stranded helicate containing major and minor grooves reminiscent of B-DNA (Hydrogen atoms and non-coordinating anions are not shown for clarity).

one sodium ion and two strands of ortho-linked hexaphenolate as the ligand. The complex $\mathbf{1 6}$ has $D_{2}$ symmetry with three mutually perpendicular $C_{2}$ axes. The two strands are $C_{2}$ symmetric, structurally identical, and are bridged by the spiroborates formed from the terminal biphenol units and the boron atoms. Interestingly, an octacoordinated sodium cation is found at the center (Figure 13).

Domer et al., reported a subcomponent assembly and transmetalation of dinuclear helicates. ${ }^{19}$ Thiosalicylaldimine based ligand synthesized via metal-template (Zn(II) or Ni(II)) controlled reactions of mercaptobenzaldehyde and a diamine formed dinuclear double-stranded complexes. Further, the formed zinc and nickel helicates undergo transmetalation with palladium acetate to afford the dinuclear palladium complex (Figure 14), which is the thermodynamically most stable helicate.

A recent report from our group describes the very first cis- $\mathrm{Pd}_{2} \mathrm{~L}_{2}^{\prime} \mathrm{L}_{2}$ 'helicate' ${ }^{20}$ with imidazole-appended bidentate ligands. Cartoon diagram shown in Figure 15 indicates how a double-stranded binuclear helicates of both handednesses, i.e., cis- $M-\mathrm{Pd}_{2} \mathrm{~L}_{2}^{\prime} \mathrm{L}_{2}$ and cis- $P-\mathrm{Pd}_{2} \mathrm{~L}_{2}^{\prime} \mathrm{L}_{2}$ could be logically explained from a plateau type non-helical architecture.

The ligands are helically wrapped to form the $M$ or $P$ isomers of $\mathrm{Pd}_{2} \mathrm{~L}_{2}^{\prime} \mathrm{L}_{2}$ helicate by restraining one of the $\mathrm{PdN}_{4}$ square planes of a 'plateau'-type cis- $\mathrm{Pd}_{2} \mathrm{~L}_{2}^{\prime} \mathrm{L}_{2}$ complex coinciding with a reference plane (xy-plane) and rotating the other $\mathrm{PdN}_{4}$ square plane in either of the directions in a circular manner by an angle $\theta$ around the $\mathrm{Pd} \cdots \operatorname{Pd}$ axis (x-axis) (Figure 15). However, this is just a geometrical comparison only and not for mechanistic claims. The torsion angle $\theta$ between the two coordination $\mathrm{PdN}_{4}$ planes of a given 'helicate' is considered here as its magnitude of helicity. 


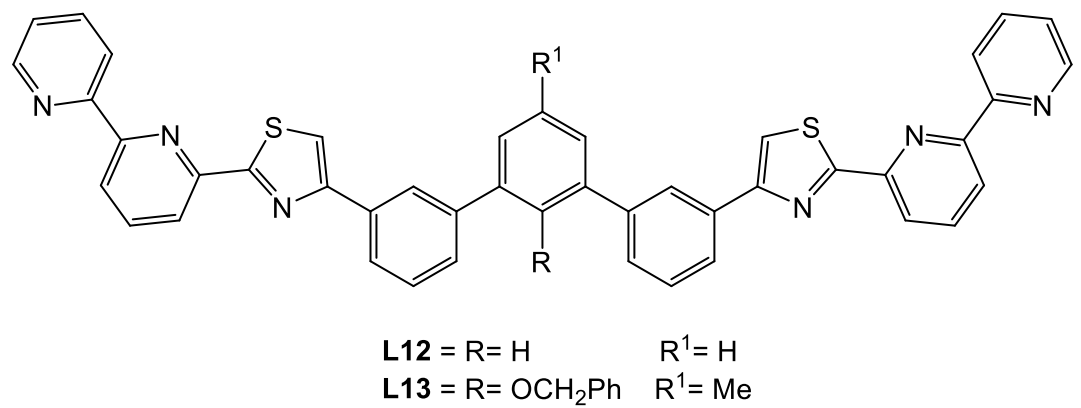

(a)

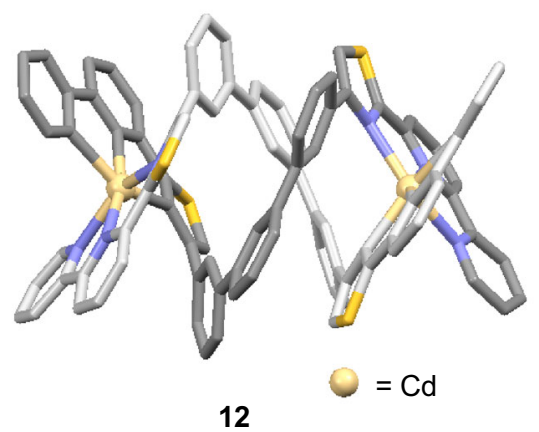

(b)

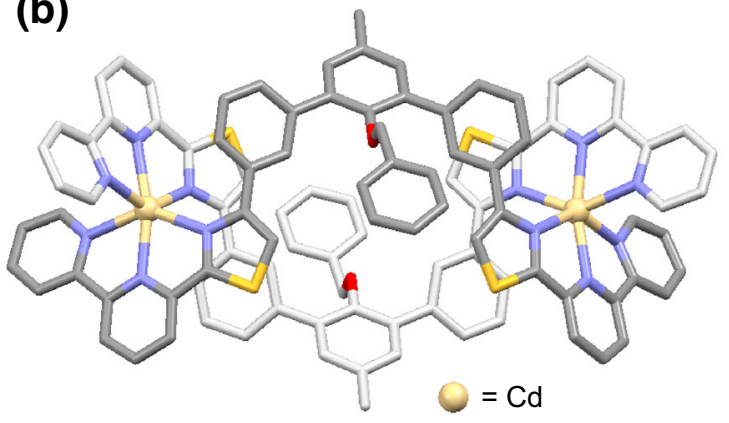

13

Figure 10. Ligands L12, L13: (a) crystal structure of $\left[\mathrm{Cd}_{2}(\mathbf{L 1 2})_{2}\right]\left(\mathrm{ClO}_{4}\right)_{4}, 12$ a binuclear double-stranded helicate; (b) crystal structure of $\left[\mathrm{Cd}_{2}(\mathbf{L 1 3})_{2}\right]\left(\mathrm{ClO}_{4}\right)_{4}, 13$ a binuclear double-stranded mesocate (Hydrogen atoms and non-coordinating anions are not shown for clarity).

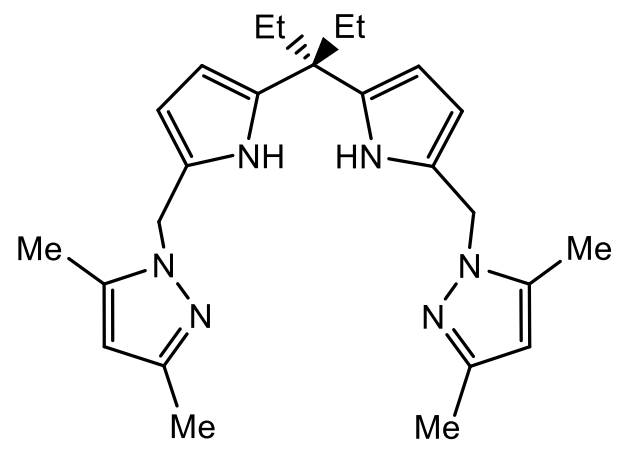

L14

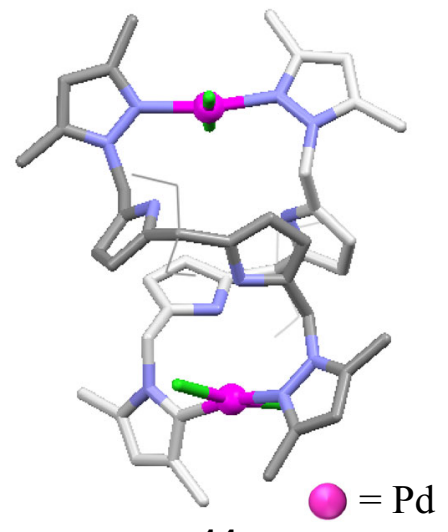

14

Figure 11. Ligand $\mathbf{L 1 4}$ and crystal structure of $\left[\mathrm{Pd}_{2}(\mathbf{L 1 4})_{2} \mathrm{Cl}_{4}\right]$, a binuclear double-stranded helicate (Hydrogen atoms and non-coordinating anions are not shown for clarity).

A flexible (1H-imidazolyl)methyl appended bidentate nonchelating ligand L18 on complexation with palladium(II) formed a rare variety of binuclear helicate, $\mathbf{1 8}$ as shown in Figure $16 .{ }^{20}$ Hence, the various factors which govern the formation of a binuclear double-stranded helicate of the type $\operatorname{Pd}_{2} L_{2}^{\prime} L_{2}$ has to be probed. The probable factors which can govern the formation of a binuclear double-stranded helicate of the type $\mathrm{Pd}_{2} \mathrm{~L}_{2}^{\prime} \mathrm{L}_{2}$ are cis-protecting group, a counter anion, length of the ligand, substituent on ligand, the concentration of the reactants (metal and ligand) and solvent. The length of the spacer in the imidazole appended ligands were modified and the resulting $\operatorname{Pd}_{2} \mathrm{~L}_{2}^{\prime} \mathrm{L}_{2}$ type architecture was analysed by Naranthatta et al., 2016. ${ }^{20}$

A few reports on double-stranded trinuclear helicates are also available in the literature. ${ }^{21}$ Some higher nuclear doublestranded helicates are also possible.

Chiral $2,2^{\prime}: 6^{\prime}, 2^{\prime \prime}$-terpyridines were treated with silver(I) in less coordinating solvents such as methanol or 
nitromethane, to give bis(double helicates) $\left[\left\{\mathrm{Ag}_{2}(\mathbf{L 1 9})_{2}\right\}_{2}\right]$ $\left(\mathrm{PF}_{6}\right)_{4}, 19 .{ }^{12 \mathrm{a}}$ The tendency for the formation of $\mathrm{Ag} \cdots \mathrm{Ag}$ interactions result in a subsequent aggregation process to give tetranuclear species in the solid state. The system is found to be solvent dependent, for instance in acetonitrile, mononuclear $[\mathrm{Ag}(\mathbf{L 1 9})(\mathrm{MeCN})]\left(\mathrm{PF}_{6}\right)$ is formed (Figure 17).

\subsection{Triple-stranded helicates}

Triple-stranded helicates can be further subdivided into binuclear triple-stranded metallohelicates and trinuclear triplestranded metallohelicates by exploiting the number and nature of the chosen ligands and metal ions. Few higher nuclear triple stranded metallohelicates were also found. Few representative examples for triple-stranded metallohelicates ${ }^{22-26}$ are reported.

Roberts et al., prepared a kinetically metastable $\mathrm{Fe}_{2} \mathrm{~L}_{3}$ type triple helicates ${ }^{23}$ by subcomponent self-assembly of iron(II) salts, 2-formylpyridine, and a three-fold-symmetric tris-aniline at 2:6:3 ratio. Condensation of the aldehyde with the tris-aniline at 6:3 ratio allowed the formation of a Schiff

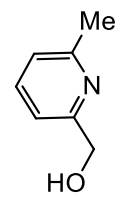

HL15

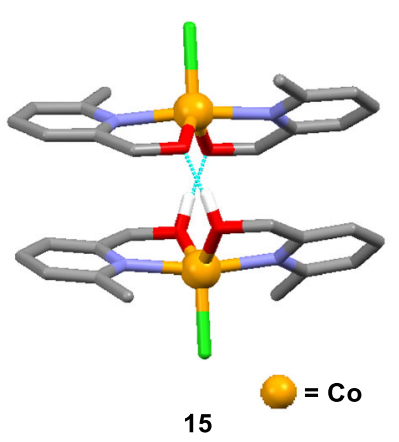

Figure 12. Ligand L15 and crystal structure of $\left[\mathrm{Co}(\mathrm{HL15})_{2} \mathrm{Cl}\right]\left[\mathrm{Co}(\mathbf{L} 15)_{2} \mathrm{Cl}\right], \mathbf{1 5}$ a binuclear double-stranded helicate where ligand backbone was build up by hydrogen-bonding of simple pyridine-alcohol precursors (Hydrogen atoms (except hydrogen bonded hydrogens) and non-coordinating anions are not shown for clarity). base ligand where one aniline unit is still untouched. The meta-stable helicate remained in equilibrium with the thermodynamically favoured $\mathrm{Fe}_{4} \mathrm{~L}_{4}$-type face-capped tetrahedron. The reaction of the aniline residues of the metastable helicate with different electrophiles, disturbs the equilibration process, thereby endowing the helicate with additional functionality. For instance, the unreacted aniline units in the metastable helicate could be acetylated using acetic anhydride to afford $\mathbf{2 0}$ where the coordinated ligand is post-modified to become $\mathbf{L 2 0}$ (Figure 18).

A tris(bipyridine) ligand L21 with two BINOL groups has been prepared by Gütz et al., in two enantiomerically pure forms. ${ }^{24}$ Here, two BINOL groups are used as stereogenic elements (BINOL $=2,2^{\prime}$-dihydroxy-1, $1^{\prime}$-binaphthyl). Ligand $(P, P)$-L21 undergoes completely diastereoselective self-assembly into $D 3$-symmetric $(\Delta, \Delta, \Delta)$-triple-stranded trinuclear helicates (Figure 19) upon coordination to iron(II). Similarly $(M, M)$-configured ligand gives rise to $(\Lambda, \Lambda, \Lambda)$.

Homochiral helicates have the same chirality at all the metal centers, whereas heterochiral mesocates have an even number of metal centers with a mirror plane at the center of the helicate, which makes them achiral meso form. A special variety of helicate, called side-by-side helicates can be synthesized if the mesocates are extended into helicates with an odd number of metal centers. The odd number of metal centers with alternating $\Delta$ and $\Lambda$ chirality makes the helicate overall chiral, and the ligands do not wind around the helix but rather bind in a parallel zigzag fashion. Rigid chelating ligands or ligands with spacers having an odd number of atoms between the chelating units are generally used to synthesize this variety of helicates. ${ }^{1 \mathrm{~d}}$

A linear hybrid tris-bidentate neutral ligand having 2, 2'bipyridine and two terminal triazolyl pyridine chelating units separated by methylene spacer (L22) was used to synthesize trinuclear triple-stranded homometallic side-by-side helicates ${ }^{25}$ with iron(II) and zinc(II) respectively. The same group has also reported the first example of heterometallic trinuclear triple-stranded side-by-side helicates. The self-sorting behaviour of the hybrid ligand toward the two different metal ions selects the specific formation of $\left[\mathrm{Fe}_{2} \mathrm{Zn}(\mathbf{L 2 2})_{3}\right](\mathrm{OTf})_{6}$, 22 (Figure 20).<smiles>CCCCCCC(C)(C)C</smiles>

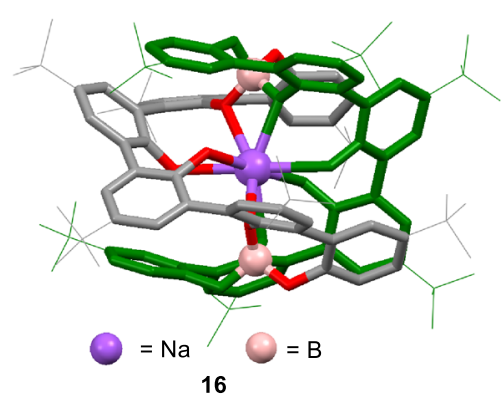

Figure 13. Ligand $\mathrm{H}_{6} \mathbf{L 1 6}$ and crystal structure of $\mathrm{H}\left[\mathrm{B}_{2} \mathrm{Na}\left(\mathrm{H}_{2} \mathbf{L} \mathbf{1 6}\right)_{2}\right], \mathbf{1 6}$ a trinuclear double-stranded helicate. (Hydrogen atoms and non-coordinating anions are not shown for clarity). 
(a)
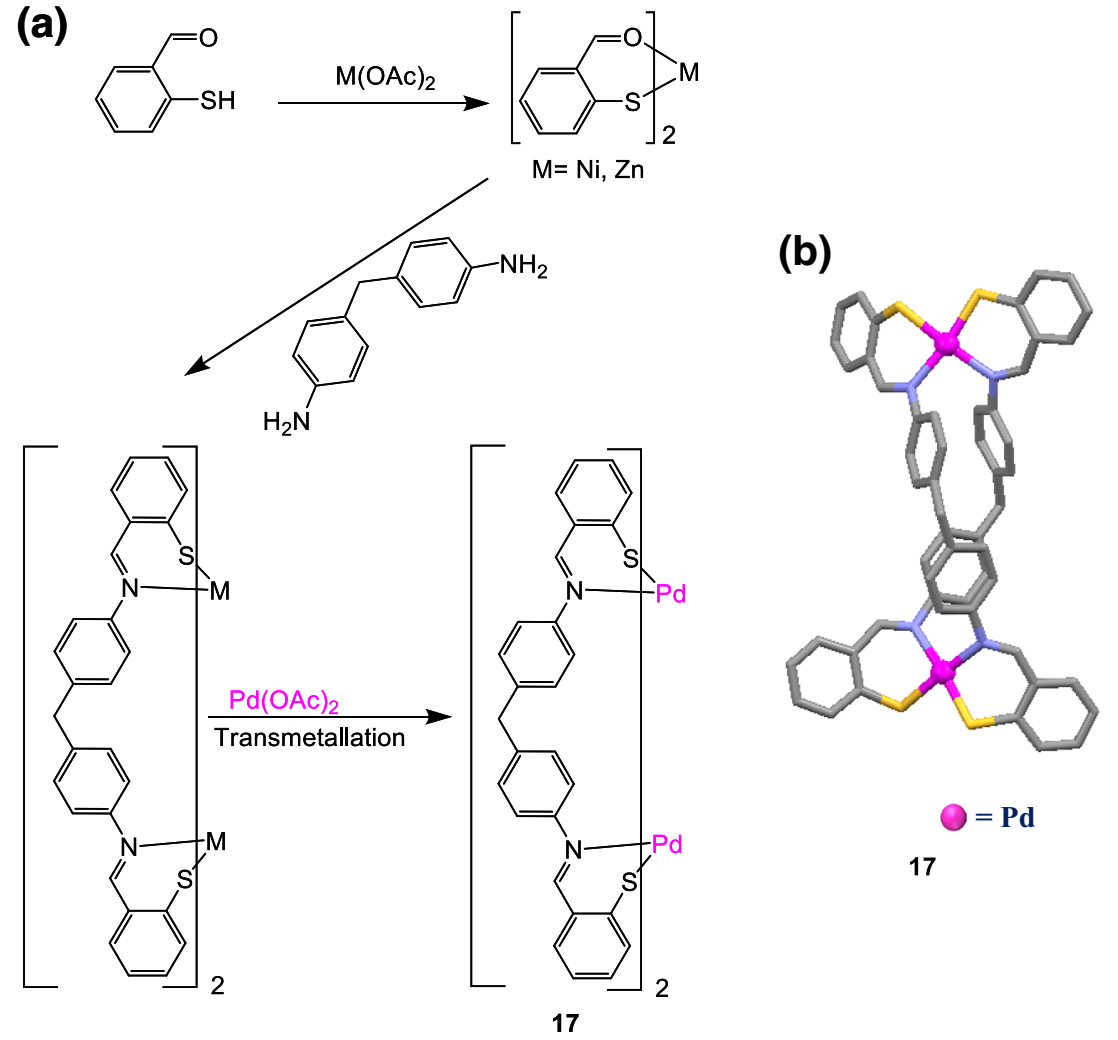

Figure 14. (a) Sub-component self-assembly via formation of $\left[\mathrm{Ni}_{2}(\mathbf{L} \mathbf{1 7})_{2}\right]$ or $\left[\mathrm{Zn}_{2}(\mathbf{L} \mathbf{1 7})_{2}\right]$ followed by transmetallation using $\mathrm{Pd}(\mathrm{OAc})_{2}$. (b) X-ray structure of $\left[\mathrm{Pd}_{2}(\mathbf{L 1 7})_{2}\right], \mathbf{1 7}$, a double-stranded helicate (Hydrogen atoms and non-coordinating anions are not shown for clarity).

(b)

(a)

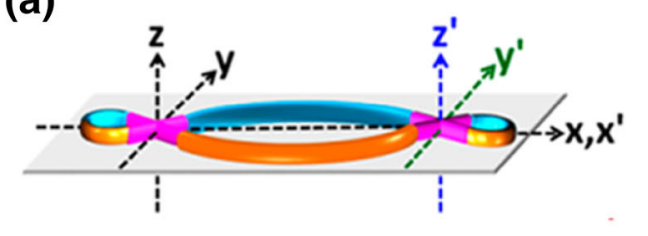

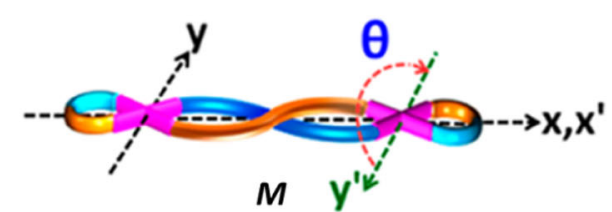

$\int_{-1}^{\theta}$

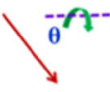

(c)

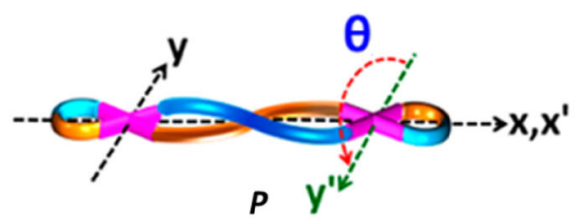

Figure 15. Cartoon representation of $\mathrm{Pd}_{2} \mathrm{~L}_{2}^{\prime} \mathrm{L}_{2}$ complexes representing the relative positions of the $\mathrm{PdN}_{4}$ square planes in (a) 'plateau'; (b) $M$ isomer of $\mathrm{Pd}_{2} \mathrm{~L}_{2}^{\prime} \mathrm{L}_{2}$ helicate (from plateau) type architectures; (c) $P$ isomer of $\mathrm{Pd}_{2} \mathrm{~L}_{2}^{\prime} \mathrm{L}_{2}$ helicate (from plateau) type architectures. ${ }^{20}$

Bodman and Fitchett reported a series of $\mathrm{M}_{2} \mathrm{~L}_{3}$ triplestranded helicates $(\mathbf{2 3}, \mathbf{2 4})^{26}$ using zinc as the labile metal component and ligands that retain the symmetry of the coordination sites, with a particular focus on the effect of the addition of steric bulk in the spacer remote from the coordinating system (Figure 21). In these particular rigid ligands, a twist on opposite faces of the pyridazine ring is required for the formation of helicates, while a twist on the same side leads to 


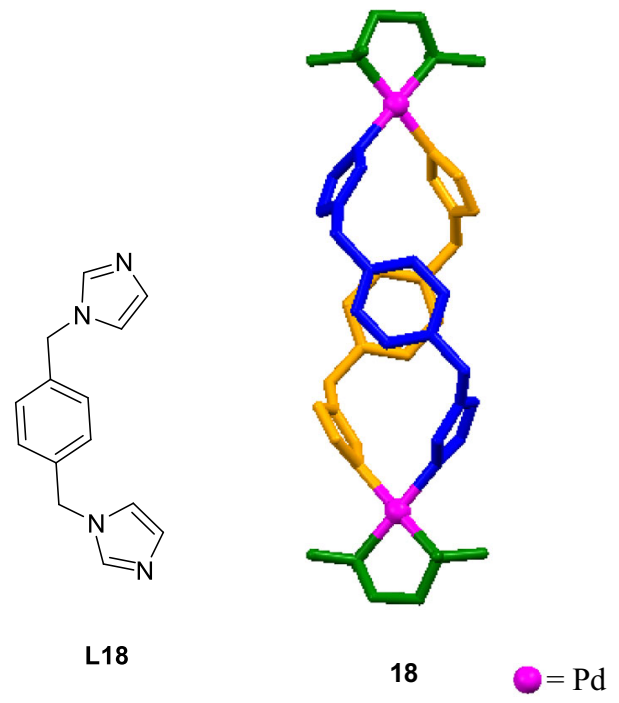

Figure 16. Ligand L18 and crystal structure of $\left[\mathrm{Pd}_{2}(\mathbf{L 1 8})_{2}\right]\left(\mathrm{ClO}_{4}\right)_{4}, \mathbf{1 8}$ a binuclear double-stranded helicate (Hydrogen atoms and non-coordinating anions are not shown for clarity).

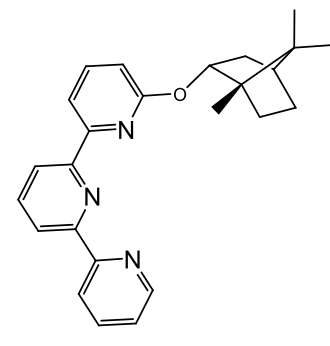

L19

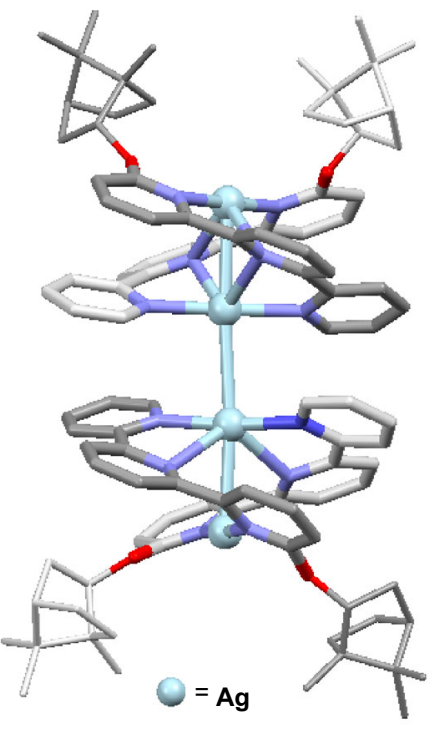

19
Figure 17. Ligand L19 and crystal structure of $\left[\left\{\mathrm{Ag}_{2}(\mathbf{L 1 9})_{2}\right\}_{2}\right]\left(\mathrm{PF}_{6}\right)_{4}, \mathbf{1 9}$ a tetranuclear double-stranded helicate (Hydrogen atoms and non-coordinating anions are not shown for clarity).

the [2 $\times 2]$-grid, 25. Greater steric bulk induces larger twists which disfavour the formation of triple helicates compared to $[2 \times 2]$-grids.

\subsection{Quadruple-stranded helicates}

In quadruple-stranded helicate four ligand strands wrap around the metal centers in a helical fashion. When compared to double and triple stranded helicates, the quadruple stranded helicates are $\mathrm{few}^{2 \mathrm{e}, 27-31}$ with metals like chromium, nickel, copper, palladium, silver, and thorium. Representative examples are discussed below.

Self-assembly of bridging bidentate ligand $N, N^{\prime}$ (pyridine-2,6-diyl)dinicotinamide, L26 with palladium(II) afforded a quadruple-stranded metallo-helicate, $\mathbf{2 6}^{2 \mathrm{e}}$ in which both the $M$ and $P$ helicates exist in the crystal structure (Figure 22). However, the two enantiomeric forms are most likely equilibrating in solution.

A self-selecting homochiral quadruple-stranded copper helicate, ${ }^{27 \mathrm{~d}} 27$ was constructed using L-3,3',4,4'-biphenylsulfonediimides $\left(\mathrm{L}-\mathrm{H}_{2} \mathbf{L} 27\right)$ substituted with amino acids (Figure 23). It was observed that the reaction of a D/L ligand mixture results in the self-selective formation of the enantiomeric cages. Thus, the homochirality of the $\mathrm{M}_{4} \mathrm{~L}_{4}$ helical cages is based on the handedness of the ligands employed.

Fukuda et al., synthesised the first interlocked metallohelicate in 2008 which was quadruple-stranded. ${ }^{29} \mathrm{~A}$ quadruply stranded metallohelicate formed from $\mathrm{Pd}\left(\mathrm{NO}_{3}\right)_{2}$ and 4,4'-bis(3-pyridinemethoxy)benzophenone $\mathbf{L 2 8}$ spontaneously undergo dimerization to obtain an interlocked metallohelicate, $\mathbf{2 8}$ which retains its interlocked structure in solution also (Figure 24).

An $\mathrm{M}_{2} \mathrm{~L}_{4}$ helical capsule, 29 shown in Figure 25 was introduced by Kishi et al., in 2011 with four bis-anthracene ligands and two palladium(II) ions. ${ }^{30}$ The self-assembled palladium(II) helical capsule possesses a cavity with a diameter of $\sim 1 \mathrm{~nm}$ which can encapsulate spherical and planar molecules (medium size) as well as a very large molecule $\left(\mathrm{C}_{60}\right)$.

Crowley et al., have reported a quadruple-stranded $\mathrm{M}_{2} \mathrm{~L}_{4}$ helicate, ${ }^{31}$ showing the self-assembly of two palladium(II) units and four 1,2,3-triazole donor units (Figure 26). As expected the $\mathrm{N} 3$ nitrogen atoms of the triazole ligands coordinates to palladium(II) in a distorted square-planar coordination environment. The ligand units are twisted approximately $45^{\circ}$ out of the square plane and this twisting generates the overall helical structure with a helical pitch of $90^{\circ}$. The helicate is further stabilised by many face-to-face $\pi-\pi$ stacking interactions (the centroid-centroid distances $=3.646-$ $4.089 \AA)$.

A small series of $\left[\mathrm{Pd}_{2}(\mathbf{L} \mathbf{3 0}-\mathbf{L} \mathbf{3 2})_{4}\right]\left(\mathrm{BF}_{4}\right)_{4}, \quad \mathbf{3 0 - 3 2}$, quadruple-stranded, dipalladium(II) architectures (Figure 26) were screened for their cytotoxic effects against cancer cell line and non-malignant line, respectively. The most cytotoxic complex is $\left[\mathrm{Pd}_{2}(\mathbf{L 3 1})_{4}\right]\left(\mathrm{BF}_{4}\right)_{4}, \mathbf{3 1}$ with hexane substituent, possessing low micromolar $\mathrm{IC}_{50}$ values against the cell lines tested, while the other helicates displayed moderate or no cytotoxicity. ${ }^{28 \mathrm{~d}}$ Preliminary mechanistic studies indicate that 31 does not induce cell death in the same way as clinically used metal complexes such as cisplatin. Instead of interacting with DNA, 31 appears to disrupt the cell membrane. 


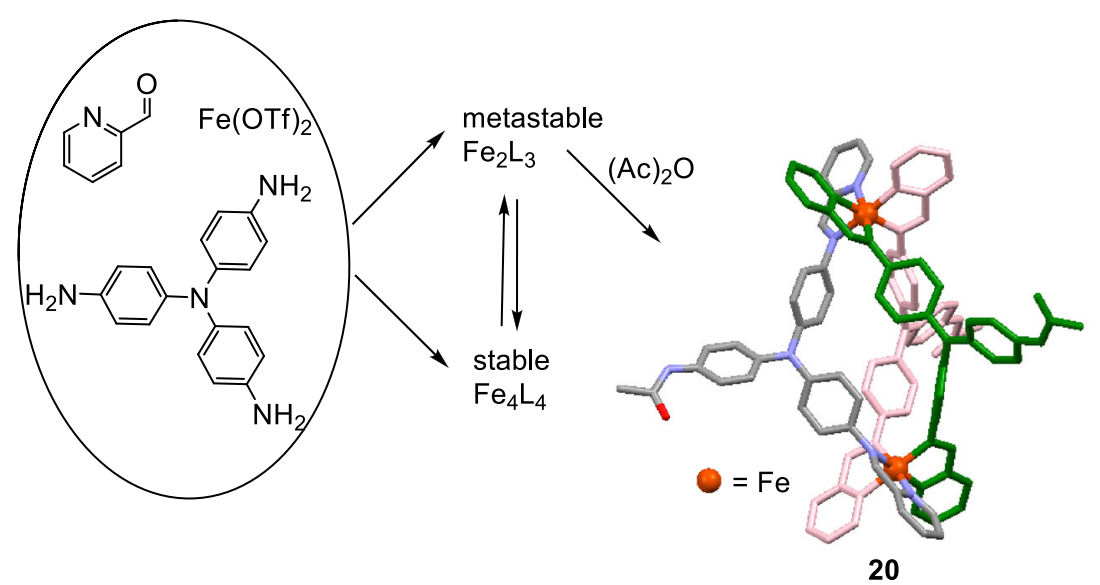

Figure 18. Synthesis and crystal structure of $\left[\mathrm{Fe}_{2}(\mathbf{L 2 0})_{3}\right](\mathrm{OTf})_{4}, 20$ a binuclear triple-stranded helicate formed from sub-component self-assembly (Hydrogen atoms and non-coordinating anions are not shown for clarity).

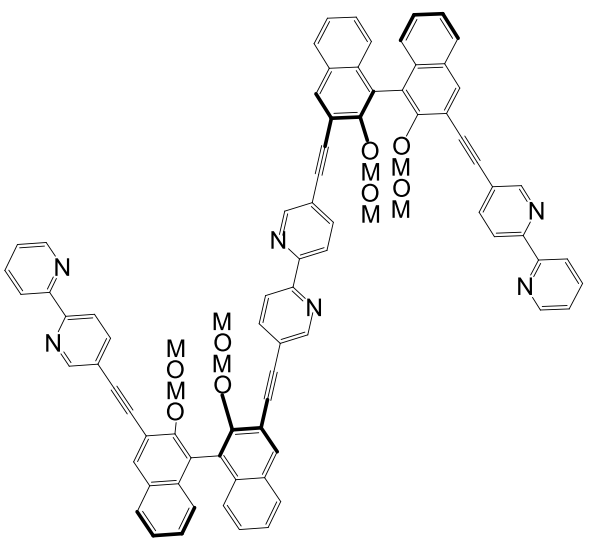

L21

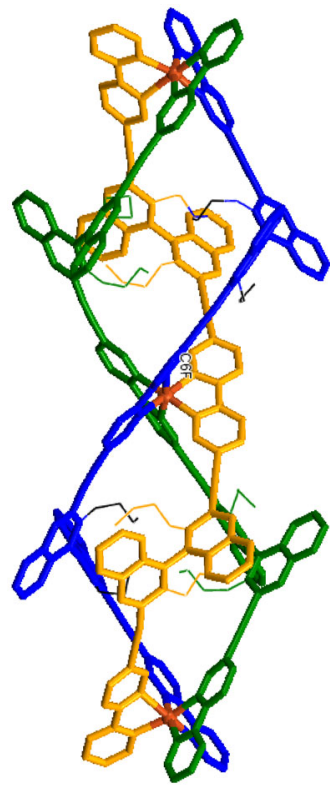

$=\mathrm{Fe}$

21

Figure 19. Ligand $(P, P)$-L21 and crystal structure of $(\Delta, \Delta, \Delta)-\left[\mathrm{Fe}_{3}(\mathbf{L 2 1})_{3}\right](\mathrm{F})_{6}, 21$ a trinuclear triple-stranded helicate (Hydrogen atoms and non-coordinating anions are not shown for clarity).

\subsection{Circular helicates}

Circular/cyclic helicates have their helicating ligands in a closed cyclic manner ${ }^{1 \mathrm{~d}}$ (Figure 27). These have a clear sense of left- or right-handedness arising from the weaving of the ligand threads around metal centers. Cartoon diagram of a few circular helicates are shown in Figure 27. At a given metal center, two or more ligand moieties meet for complexation with a metal corner.

Generally, the DNA double helix is acyclic but it can also exist as a cyclic structure called circular DNA, as found in some viruses. Henceforth, it would be of great interest to design closed, circular helicates. ${ }^{32} \mathrm{~A}$ few representative examples for circular helicates ${ }^{32-36}$ are discussed below.

Baum and co-workers studied the complexation of $\mathrm{Cu}(\mathrm{I})$ with a chiral 1,2-ethanediyl-spaced quaterpyridine ligand L33. The complexation recation resulted in a library of bi- and higher nuclear complexes having formula $[\mathrm{Cu} \mathbf{L} 33]_{\mathrm{n}}^{\mathrm{n}+}(n=2$, $3,4,5) .{ }^{33}$ The trinuclear complex i.e. $\left[\mathrm{Cu}_{3}(\mathbf{L} \mathbf{3 3})_{3}\right]\left(\mathrm{PF}_{6}\right)_{3}$ got crystallized from the reaction mixture revealing the formation of a cyclic helicate (Figure 28). The three copper centers are located in the corners of a triangular arrangement and the coordination geometry around each metal center is distorted tetrahedral (bite angles $80.0-82.4^{\circ}$ ) with $\mathrm{Cu} \cdots \mathrm{Cu}$ distances 
of 6.905-6.983 $\AA$. The $\mathrm{Cu}-\mathrm{N}$ distance is 1.981-2.048 $\AA$. The pinene groups point outwards giving the cation an outer diameter of $c a .20 .5 \AA$ and a height of $8 \AA$.

Childs and co-workers reported self-assembly of a nanosize chiral ball ${ }^{32 \mathrm{c}}$ through supramolecular aggregation of

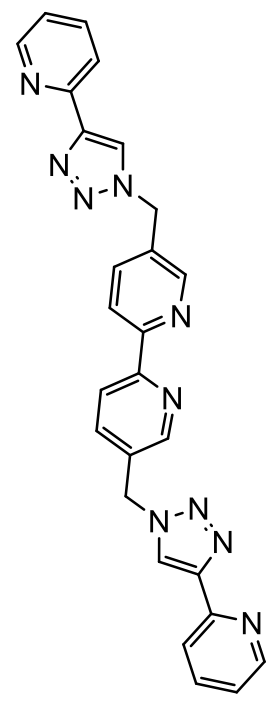

L22

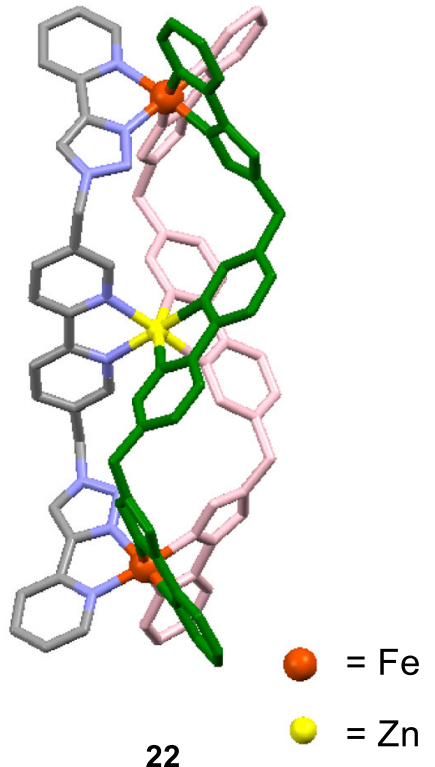

22<smiles>O=C(Nc1cccnc1)c1cccc(C(=O)Nc2cccnc2)n1</smiles>

L26

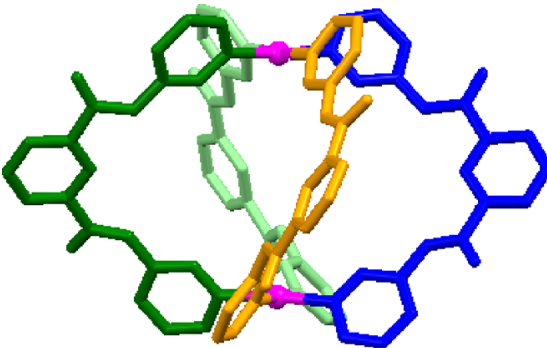

26 triangular circular helicate, $\mathbf{3 4}$ which is bowl-shaped. Each copper(I) center, is four-coordinate, in a pseudo-tetrahedral coordination environment bound to two pyridylimine units from two different ligands (Figure 29). The ligands wrap above and below the plane formed by the three copper centers forming a trinuclear circular helicate. Totally six $\mathrm{CH}-\pi$ interactions are there within the triangle between the methyl groups of one ligand and the phenyl rings of an adjacent ligand and probably contributing to the energetic stability of circular helicate.

Figure 22. Ligand L26, $X$-ray structure of $\left[\mathrm{Pd}_{2}(\mathbf{L 2 6})_{4}\right]\left(\mathrm{NO}_{3}\right)_{4}, \quad 26$ showing a quadruple-stranded helicate. (Hydrogen atoms and anions are not shown for clarity).<smiles>c1ccc(-c2ccc(-c3ccccn3)nn2)nc1</smiles>

L23<smiles>CC(C)(C)c1cccc(-c2nnc(-c3ccccn3)c3c2CCC3)n1</smiles>

L24<smiles>c1ccc(-c2nnc(-c3ccccn3)c3c2CCCC3)nc1</smiles>

L25

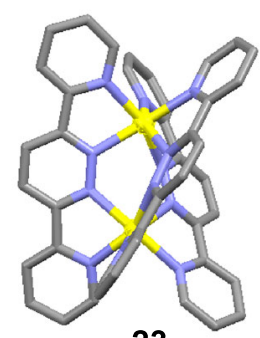

23

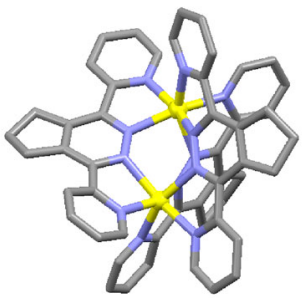

24

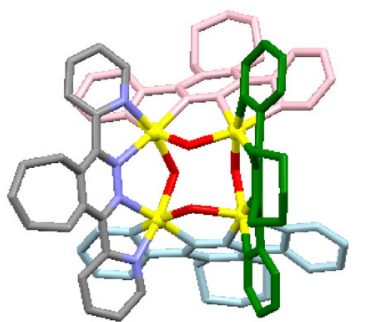

25

$$
=\mathrm{Zn}
$$

Figure 21. Ligands L23, L24, $\mathbf{L 2 5}$ and crystal structure of $\left[\mathrm{Zn}_{2}(\mathbf{L 2 3})_{3}\right]\left(\mathrm{ClO}_{4}\right)_{4}, \mathbf{2 3} ;\left[\mathrm{Zn}_{2}(\mathbf{L 2 4})_{3}\right]\left(\mathrm{ClO}_{4}\right)_{4}, 24$ binuclear triple-stranded helicates and $\left[\mathrm{Zn}_{4}(\mathbf{L 2 5})_{4}(\mathrm{OH})_{2}\left(\mathrm{H}_{2} \mathrm{O}\right)_{2}\right]\left(\mathrm{ClO}_{4}\right)_{6}, 25$ a $2 \times 2$ grid (Hydrogen atoms and non-coordinating anions are not shown for clarity). 


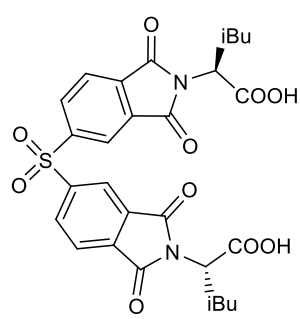

$\mathrm{L}-\mathrm{H}_{2} \mathbf{L} 27$

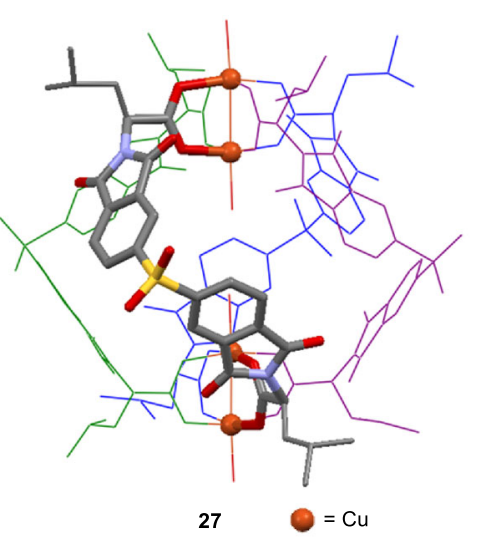

$27 \quad \mathrm{O}=\mathrm{Cu}$

Figure 23. L-leucine-derived ligand $\mathrm{H}_{2} \mathbf{L} 27$ and X-ray structure of $\Lambda$-[ $\left.\mathrm{Cu}_{4}(\mathrm{~L}-\mathrm{L} 27)_{4}\right], 27$ showing a quadruple-stranded helicate (coordinated solvent displayed only by the donor atom for clarity, hydrogen atoms and non-coordinating anions are not shown for clarity).

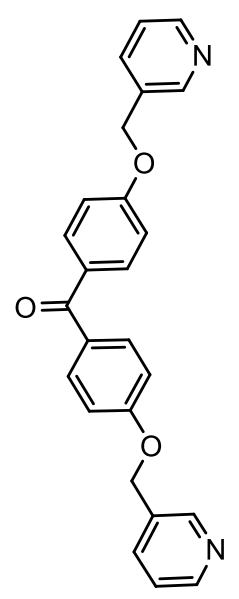

L28

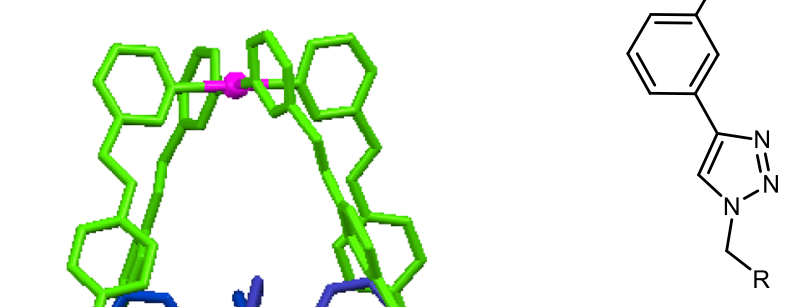

$\mathrm{R}=\mathrm{C}_{6} \mathrm{H}_{5}, \mathbf{L} \mathbf{3 0}$ $\mathrm{R}=-\mathrm{CH}_{2}\left(\mathrm{CH}_{2}\right)_{3} \mathrm{CH}_{3}, \mathbf{L} 31$

$\mathrm{R}=-\mathrm{CH}_{2} \mathrm{O}\left(\mathrm{CH}_{2}\right)_{2} \mathrm{OCH}_{3}$, L32

Figure 26. Ligand L30, X-ray structure of $\left[\mathrm{Pd}_{2}(\mathbf{L 3 0})_{4}\right]\left(\mathrm{BF}_{4}\right)_{4}, \quad 30$ showing a quadruple-stranded helicate using 1,2,3-triazole as a ligand. (Hydrogen atoms and non-coordinating anions are not shown for clarity).

A remarkable higher-nuclear $(\mathrm{ZnL35})_{10}$ circular helicate, 35 was synthesized by $\mathrm{Wu}$ and co-workers. ${ }^{34} \mathrm{Zinc}(\mathrm{II})$ centers have an overall meso-helicate structure with alternate $\Lambda$ and $\Delta$-configurations. There is no template effect by counter anions, thus the structure is solely governed by the preferred binding geometry of the zinc centers and negative charges of the ligands. Further, the neutral zinc(II) cyclic helicate can also be completely disassembled by $\mathrm{H}_{2} \mathrm{PO}_{4}$ ions (Figure 30 ).

Mobian et al., reported the synthesis of a titanium-based bowl-shaped trinuclear circular helicate, ${ }^{35}$ 36. A multicomponent self-assembly approach involving bis-biphenol strand $\left(\mathbf{H}_{4} \mathbf{L}\right.$ 36a) and 2, 2'-bipyrimidine ( $\left.\mathbf{L 3 6 b}\right)$ as ligands and [Ti(OiPr $\left.)_{4}\right]$, was used to synthesize this neutral architecture with $C_{3}$ symmetry. Three pseudo-octahedral titanium centers, coordinated by two biphenol units and one bipyrimidine ligand, forms the circular helicate. The bipyrimidine ligand L36b acts as a molecular lock by forming geometrically welldefined and thermodynamically stable titanium complex. The complex is a chiral molecule displaying either a $\mathrm{P}-\lambda \lambda \lambda$ or $\mathrm{M}-$ $\Delta \Delta \Delta$ configuration (Figure 31 ).
Four of the bowl-shaped triangular circular helicates selfassemble in a tetrahedral fashion to form a tetrameric ballshaped aggregate through $\mathrm{CH}-\pi$ interactions. Each triangular circular helicate in the ball is of identical chirality so that the overall ball-shaped structure is also chiral.

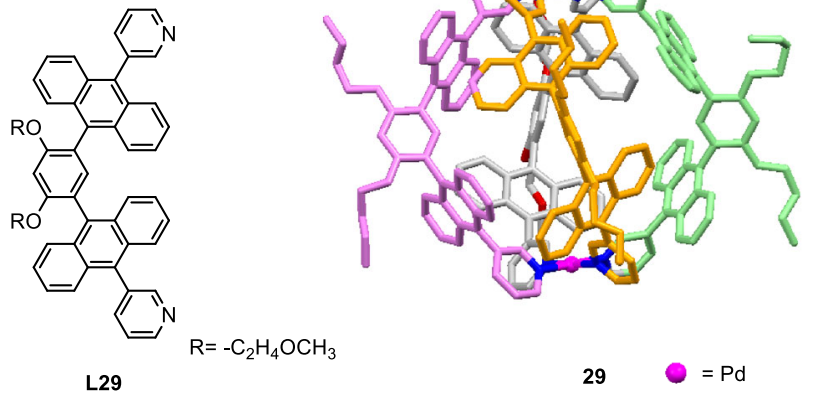

Figure 25. Ligand L29, X-ray structure of helicate. (Hydrogen atoms and non-coordinating anions are not shown for clarity).

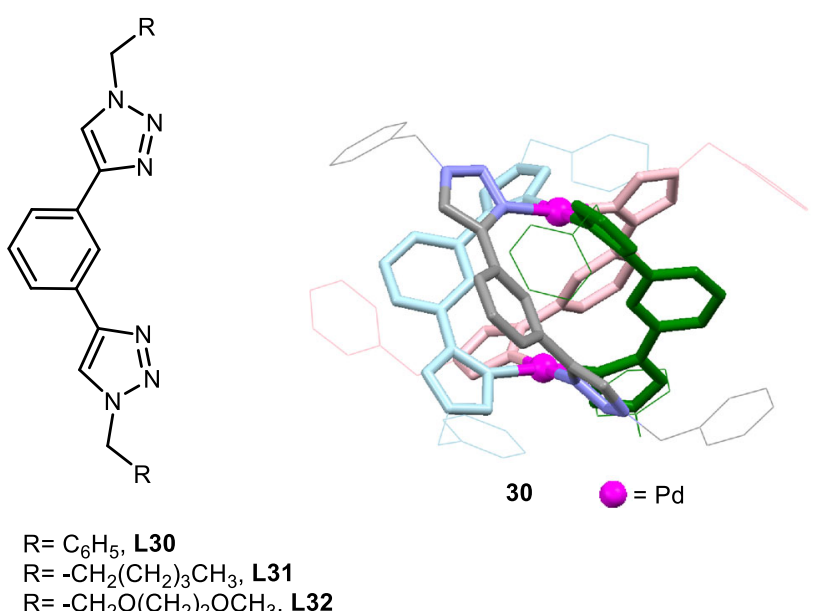

(n)

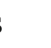



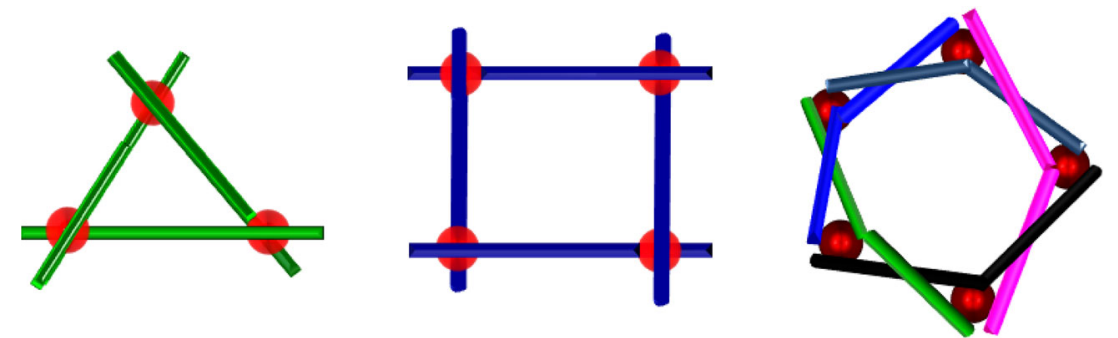

Figure 27. Cartoon diagram of typical circular helicates.
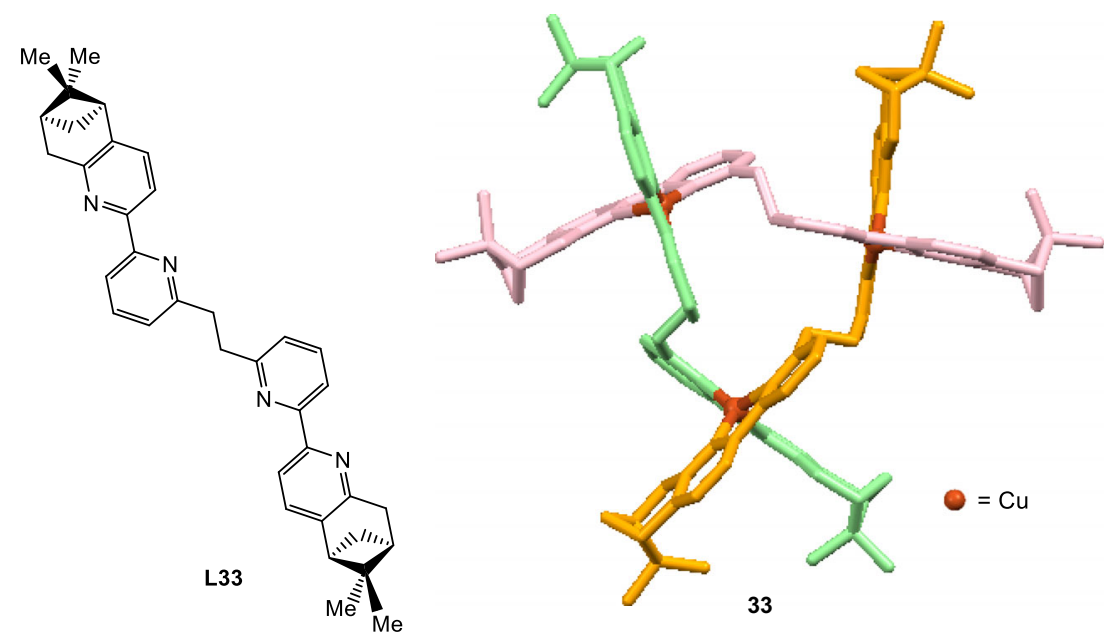

Figure 28. Ligand $\mathbf{L 3 3}$ : (a) $\mathrm{X}$-ray structure of $\left[\mathrm{Cu}_{3} \mathbf{L 3 3}_{3}\right]\left(\mathrm{PF}_{6}\right)_{3}, \mathbf{3 3}$ showing a trinuclear circular helicate (Hydrogen atoms and non-coordinating anions are not shown for clarity).

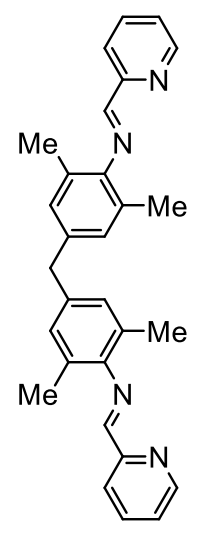

L34

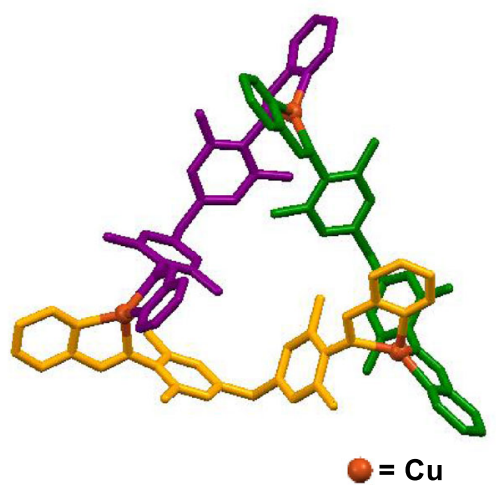

34

Figure 29. Ligand L34 and X-ray structure of $\left[\mathrm{Cu}_{3}(\mathbf{L 3 4})_{3}\right]\left(\mathrm{PF}_{6}\right)_{3}, \mathbf{3 4}$ showing a trinuclear circular helicate (Hydrogen atoms and non-coordinating anions are not shown for clarity).

Hasenknopf and co-workers introduced the first circular double helicate ${ }^{32 \mathrm{~h}}$ in 1996 (Figure 32). Five equivalents of tris-bpy ligand $\mathbf{L 3 7}$ and five equivalents of iron(II) chloride spontaneously form circular double helicate $\left[\mathrm{Cl} \subset \mathrm{Fe}_{5}(\mathbf{L 3 7})_{5}\right]$

$\left(\mathrm{PF}_{6}\right)_{9}, 37$ with chloride anion as a template. Even in the presence of large excess of another anion such as $\mathrm{PF}_{6}^{-}$or $\mathrm{CF}_{3} \mathrm{SO}_{3}^{-}$, no anion exchange takes place. Thus, $\mathbf{3 7}$ acted as a specific receptor for chloride. Each iron center has a distorted octahedral coordination sphere occupied by three "bpy" groups, two terminals and one central, belonging to three different ligand strands. All the five metal ions lie almost in one plane and form the corners of a pentagon with an edge length of $8.4 \AA$ ( $\mathrm{Fe}-\mathrm{Fe}$ distance).

Panneerselvam and co-workers introduced the first trinuclear 'intro-vertere circular helicate' ${ }^{36}$ i.e., $\left[\mathrm{Pd}_{3}(\mathrm{phen})_{3}\right.$ $\left.(\mathbf{L 3 8})_{3}\right](\mathrm{OTf})_{6}$ by complexation of $\mathrm{Pd}(\mathrm{phen})(\mathrm{OTf})_{2}$ with a triazole appended bidentate nonchelating ligand, L38. Crystal structure of $\mathbf{3 8}$ shows that all the three bound phen moieties are uniquely turned inside and lodged in the internal cavity of the molecule (Figure 33); hence the term 'introvertere circular helicate' is introduced. One of the $\mathrm{PdN}_{4}$ square planes is sandwiched between the other two via phen-inspired intramolecular $\pi$-stacking making a cylindrical stacking arrangement. A racemic pair designated as $M P P$ and $P M M$ isomers, where $M$ and $P$ stand for the handedness of the ligand $\mathrm{L}$, is observed in the crystal structure. In the crystal packing, the trinuclear intro-vertere circular helicate molecules are arranged in a columnar hexagonal stacking. The 

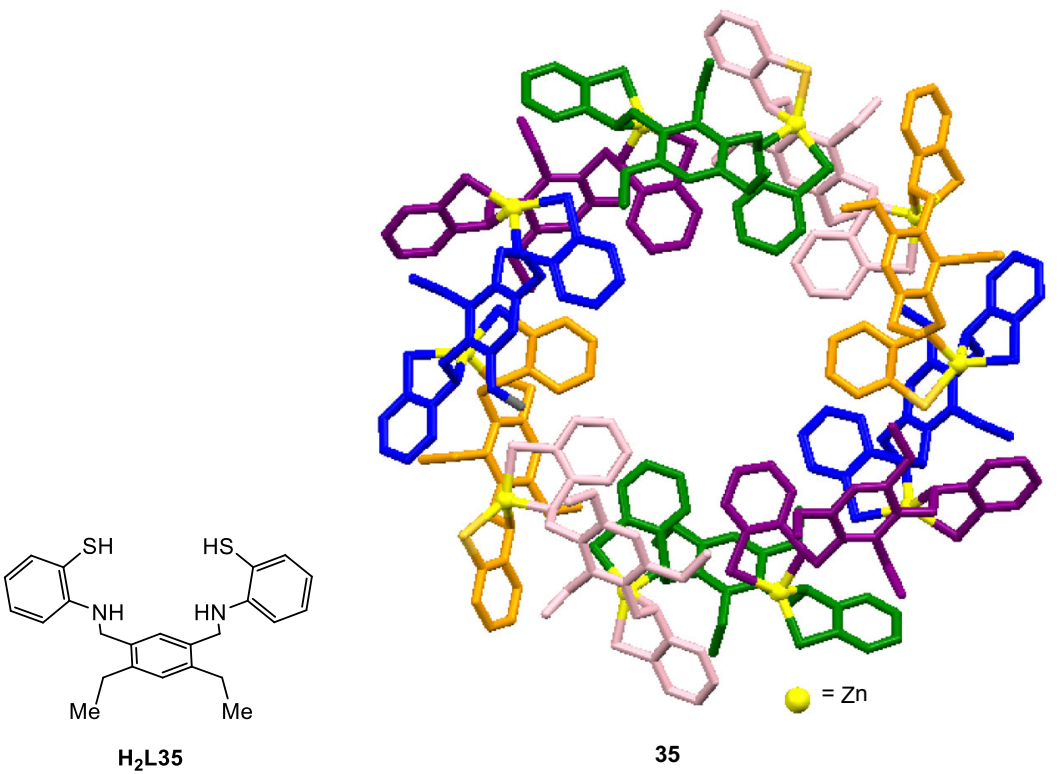

Figure 30. Ligand $\mathbf{H}_{2} \mathbf{L} 35$ and X-ray structure of $\left[\mathrm{Zn}_{10}(\mathbf{L 3 5})_{10}\right], 35$ showing a meso helicate, a special variety of circular helicate (Hydrogen atoms and non-coordinating anions are not shown for clarity).

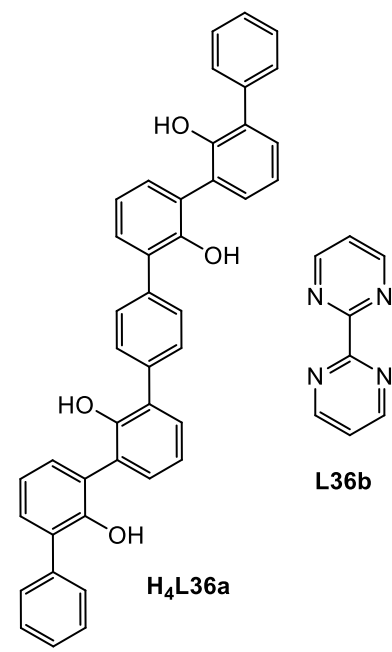

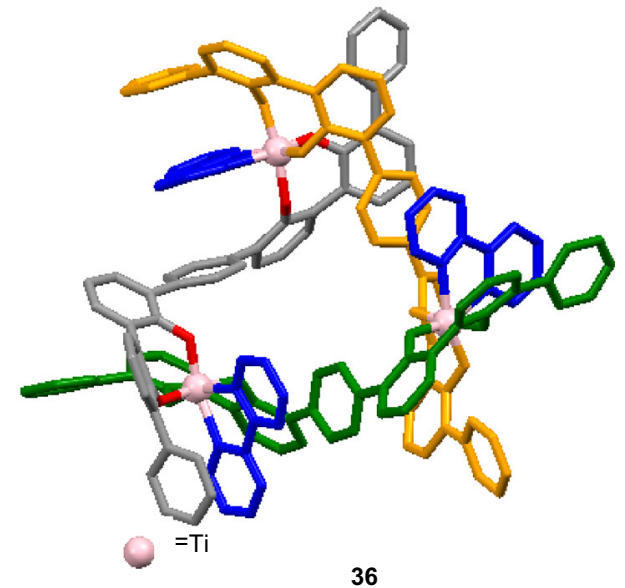

Figure 31. Ligands $\mathbf{H}_{4} \mathbf{L 3 6}$ a and L36b, and X-ray structure of a bowl-shaped circular helicate $\left[\mathrm{Ti}_{3}(\mathbf{L 3 6 a})_{3}(\mathbf{L 3 6 b})_{3}\right], \mathbf{3 6}$, formed via multicomponent self-assembly approach (Hydrogen atoms and non-coordinating anions are not shown for clarity).

two exposed phen moieties of a given molecule participated in the intermolecular $\pi$-stacking.

\subsection{Helicity modulation}

Albrecht et al., has made a systematic study for the stereospecific preparation of helicates or meso-helicates, ${ }^{1 \mathrm{~d}}$ and introduced the odd-even principle. They prepared alkylbridged dicatechol, di-8-hydroxyquinoline, or dibipyridine ligands with alkyl spacers of different length (Figure 34), and owing to the preferred zigzag conformation of the alkyl chain, the diastereoselectivity of the complex formation can be controlled. ${ }^{37}$ For chirogenic metal centers, they introduced the concept for the stereo control of helicate versus meso-helicate formation. Long dicatechol imine ligands possessing rigid 
<smiles>Cc1ccc(-c2ccc(CCc3ccc(-c4ccc(CCc5ccc(-c6ccc(C)cn6)nc5)nc4)nc3)nc2)nc1</smiles>

(a)

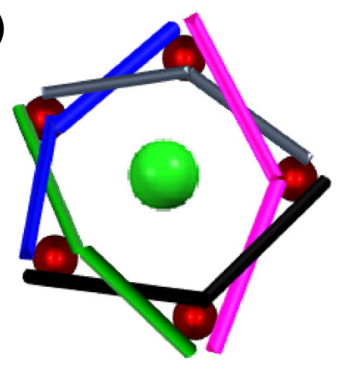

(b)

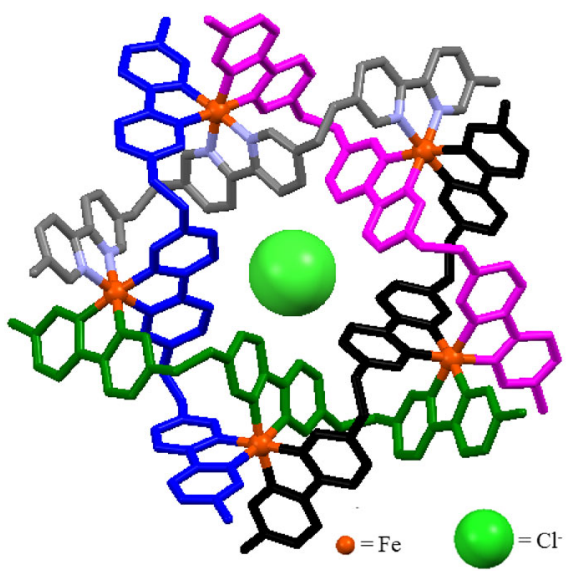

37

Figure 32. Ligand L37; (a) Cartoon diagram, (b) X-ray structure of $\left[\mathrm{Cl} \subset \mathrm{Fe}_{5}(\mathbf{L 3 7})_{5}\right]\left(\mathrm{PF}_{6}\right)_{9}, \mathbf{3 7}$ showing a double-stranded circular helicate (Hydrogen atoms and non-coordinating anions are not shown for clarity).

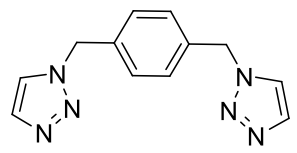

L38

(a)

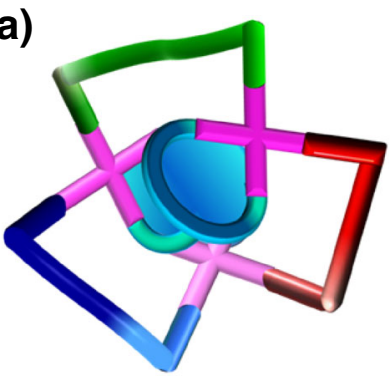

(b)

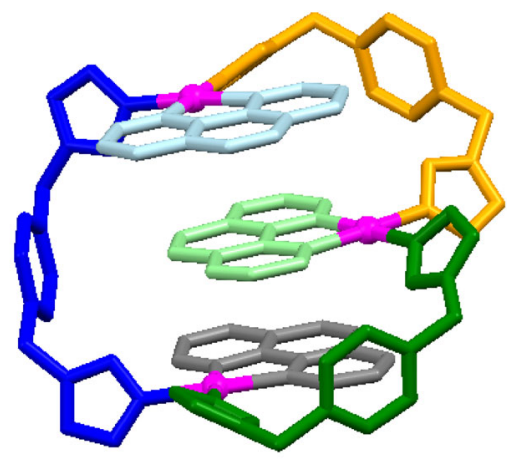

38

$=P d$

Figure 33. Ligand L38; (a) Cartoon diagram, (b) X-ray structure of $\left[\mathrm{Pd}_{3}(\text { phen })_{3}(\mathbf{L 3 8})_{3}\right](\mathrm{OTf})_{6}, 38$ showing an intro-vertere circular helicate (Hydrogen atoms and non-coordinating anions are not shown for clarity).

linear connecting units and small $\left(\mathrm{CH}_{2}\right.$ or $\left.\mathrm{CH}_{2} \mathrm{CH}_{2}\right)$ stereo controlling units were chosen.

The stereochemical information of one metal complex unit should be transferred through a rigid linear connector (composed of the imine unit and a phenylene moiety) to a central stereo-controlling unit, which 'processes' this information and transfers it again through a linear connector to the second metal complex. The stereo-controlling unit can be either an ethylene group, which in its preferred zigzag conformation possesses a $C_{2}$ axis, which is relevant for the formation of the dinuclear helicate. A methylene unit as stereo controlling unit possesses two symmetry elements which have to be considered. The $C_{2}$ axis could favor the formation of the helicate, while a 'dominance' of the $\sigma$-plane would support the preferred formation of the meso-helicate. 

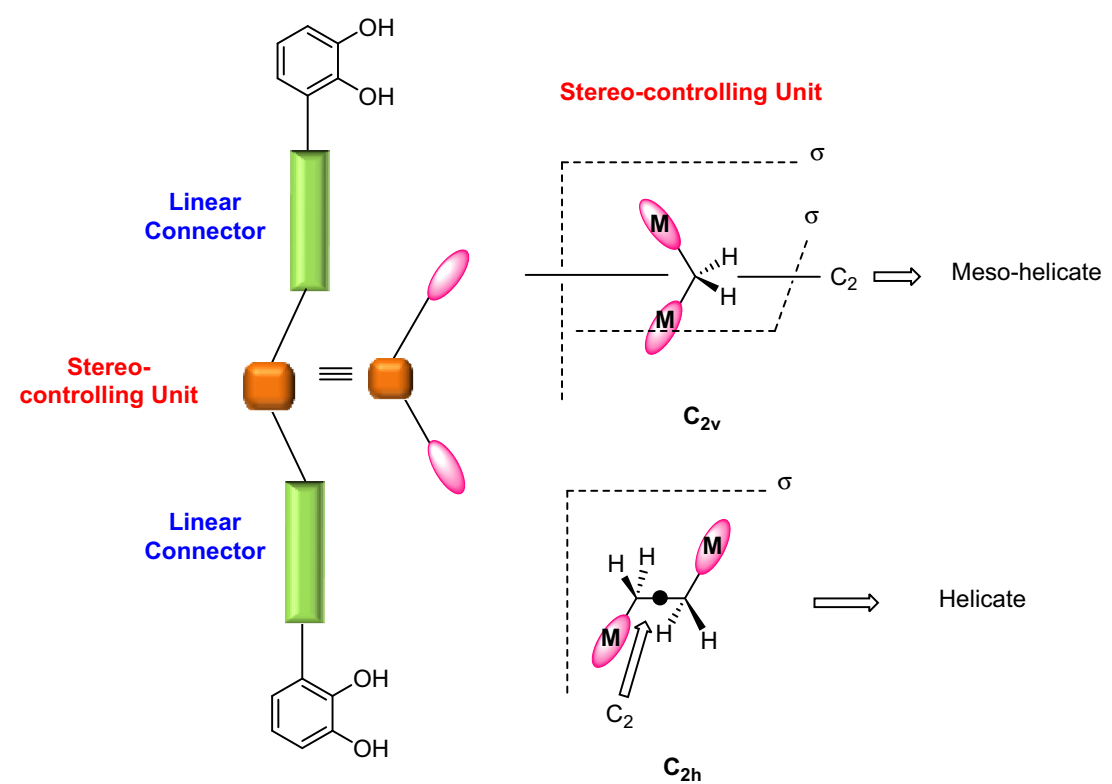

Figure 34. Cartoon diagram representing the concept for the stereo control of helicate versus meso-helicate formation with chirogenic metal centers and long dicatechol imine ligands possessing rigid linear connecting units and small $\left(\mathrm{CH}_{2}\right.$ or $\left.\mathrm{CH}_{2} \mathrm{CH}_{2}\right)$ stereo controlling units. ${ }^{37}$

\section{Conclusions}

In this review, a variety of linear and circular helicates are discussed with their structural viewpoints having both chirogenic and non-chirogenic metal centers. Linear helicates are classified based on the number of ligands wrapping around the metal centers and number of metals for a given number of strands. It was observed that circular helicates are few in number as compared to the linear helicates. Most of the helicates were found as enantiomeric pairs. However, in a few cases, stereospecific helicates were prepared using chiral ligands. The formation of helicates are controlled by steric interactions between ligand strands, special geometric features of the ligands and/or metals, also the presence of non-covalent interactions like hydrogen bonding, the $\pi-\pi$ interaction between the ligand moieties and guest templation. These features should be considered during the design and synthesis of new helicates. Helical architectures with new and novel designs including helicity modulation are anticipated upon variation of such parameters.

\section{Acknowledgements}

We thank SERB (New Delhi) for financial support (EMR/ 2017/002262).

\section{References}

1. (a) Lehn J M, Rigault A, Siegel J, Harrowfield J, Chevrier B and Moras D 1987 Spontaneous assembly of double-stranded helicates from oligobipyridine ligands and copper(I) cations: structure of an inorganic double helix Proc. Natl. Acad. Sci. 84 2565; (b) Piguet C, Bernardinelli G and Hopfgartner G 1997 Helicates as versatile supramolecular complexes Chem. Rev. 97 2005; (c) Piguet C 1999 Helicates and related metallo supramolecular assemblies: Toward structurally controlled and functional devices J. Incl. Phenom. Mol. Recognit. Chem. 34 361; (d) Albrecht M 2001 "Let's Twist Again" -double-stranded, triple-stranded, and circular Helicates Chem. Rev. 101 3457; (e) Swiegers G F and Malefetse T J 2002 Classification of coordination polygons and polyhedra according to their mode of selfassembly. 2. Review of the literature Coord. Chem. Rev. 225 91; (f) Hannon M J and Childs L J 2004 Helices and helicates: Beautiful supramolecular motifs with emerging applications Supramol. Chem. 16 7; (g) Constable E C 2013 Stereogenic metal centres-from Werner to supramolecular chemistry Chem. Soc. Rev. 421637

2. (a) Reitsamer C, Schuh W, Kopacka H, Wurst K, Ellmerer E P and Peringer P 2011 The first carbodiphosphorane complex with two palladium centers attached to the CDP carbon: Assembly of a single-stranded di-Pd helicate by the PCP pincer ligand $\mathrm{C}(\mathrm{dppm})_{2}$ Organometallics 30 4220; (b) Constable E C, Elder S M, Healy J and Ward M D 1990 Helical and nonhelical palladium(II) complexes of oligopyridine ligands: The ligand-directed assembly of polynuclear complexes $J$. Am. Chem. Soc. 112 4590; (c) Stevenson K A, Melan C F C, Fleischel O, Wang R and Petitjean A 2012 Solid-state self-assembly of triazolylpyridine-based helicates and mesocate: Control of the metal-metal distances Cryst. Growth Des. 12 5169; (d) Sahoo H S and Chand D K 2010 Conformation of $N, N^{\prime}$-bis(3-pyridylformyl)piperazine and spontaneous formation of a saturated quadruple stranded metallohelicate Dalton Trans. 39 7223; (e) 
Tripathy D, Pal A K, Hanan G S and Chand D K 2012 Palladium(II) driven self-assembly of a saturated quadruple-stranded metallohelicate Dalton Trans. 41 11273

3. (a) Constable E C 1994 Sodium springs a surprise Nature 367 415; (b) Meyer M, Kersting B, Powers R E and Raymond K N 1997 Rearrangement reactions in dinuclear triple helicates Inorg. Chem. 36 5179; (c) Amouri $\mathrm{H}$ and Gruselle M 2008 In Chirality in Transition Metal Chemistry: Molecules Supramolecular Assemblies and Materials (Chichester: John Wiley \& Sons); (d) Stein G C V, Koten G V, Vrieze K, Brevard C and Speks A L 1984 Structural investigations of silver(I) and copper(I) complexes with neutral $\mathrm{N}_{4}$ donor ligands: X-ray crystal and molecular structure of the dimer $\left[\operatorname{Ag}_{2}\{\mu-(R, S)\right.$ 1,2- $\left.(\text { py-2- } \mathrm{CH}=\mathrm{N})_{2} \mathrm{Cy}_{2}\right]\left(\mathrm{O}_{3} \mathrm{SCF}_{3}\right)_{2}$ and ${ }^{1} \mathrm{H},{ }^{13} \mathrm{C}$, and INEPT ${ }^{109} \mathrm{Ag}$ and ${ }^{15} \mathrm{~N}$ mm solution studies J. Am. Chem. Soc. 106 4486; (e) Rowan A E and Nolte R J M 1998 Helical Molecular Programming Angew. Chem. Int. Ed. 37 63; (f) Gregoliński J and Lisowski J 2006 Helicity inversion in lanthanide(III) complexes with chiral nonaaza macrocyclic ligands Angew. Chem. Int. Ed. 45 6122; (g) $\mathrm{Xu} \mathrm{J}$ and Raymond K N 2006 Structurally characterized quadruple-stranded bisbidentate helicates Angew. Chem. Int. Ed. Engl. 456480

4. Cahn R S, Ingold S C and Prelog V 1966 Specification of molecular chirality Angew. Chem. Int. Ed. 5385

5. (a) Vögtle F and Weber E 1979 Multidentate acyclic neutral ligands and their complexation Angew. Chem. Int. Ed. Engl. 18 753; (b) Akine S, Taniguchi T, Matsumoto T and Nabeshima T 2006 Guest-dependent inversion rate of a tetranuclear single metallohelicate Chem. Commun. 4961; (c) Selvakumar M P, Suresh E and Subramanian P S 2009 Single stranded helical supramolecular architecture with a left handed helical water chain in ternary copper(II) tryptophan/diamine complexes Polyhedron $\mathbf{2 8}$ 245; (d) Tashiro S, Matsuoka K, Minoda A and Shionoya M 2012 Metallo-foldamers with backbone-coordinative oxime peptides: control of secondary structures Angew. Chem. Int. Ed. 5113123

6. Kwong $\mathrm{H}-\mathrm{L}$, Yeung $\mathrm{H}-\mathrm{L}$, Lee $\mathrm{W}-\mathrm{S}$ and Wong $\mathrm{W}-\mathrm{T}$ 2006 Stereoselective formation of a single-stranded helicate: Structure of a bis(palladium-allyl)quaterpyridine complex and its use in catalytic enantioselective allylic substitution Chem. Commun. 4841

7. Saito S, Furukawa K and Osuka A 2010 Fully $\pi$ conjugated helices from oxidative cleavage of meso-arylsubstituted expanded porphyrins J. Am. Chem. Soc. 132 2128

8. Eerdun C, Hisanaga S and Setsune J -I 2013 Single helicates of dipalladium(II) hexapyrroles: helicity induction and redox tuning of chiroptical properties Angew. Chem. Int. Ed. $\mathbf{5 2} 929$

9. Akine S, Matsumoto T and Nabeshima T 2008 Spontaneous formation of a chiral supramolecular superhelix in the crystalline state using a single-stranded tetranuclear metallohelicate Chem. Commun. 4604

10. Mei G -Q, Li Y -Z, Huang K -L and Huang H -P $2006 \pi-$ Stacking of $\mu-3,3^{\prime}$-bisacetylacetonato-bis[(2,2' -bipyridine)palladium(II)] hexafluorophosphate acetonitrile solvate Acta Crystallogr. Sect. E: Struct. Rep. Online 62 $\mathrm{m} 2368$
11. Carina R F, Bernardinelli G and Williams A F 1993 Structure of a one-dimensional infinite double-helical copper(I) complex Angew. Chem. Int. Ed. Engl. 32 1463

12. (a) Baum G, Constable E C, Fenske D, Housecroft C $\mathrm{E}$ and Kulke T 1998 Solvent control in the formation of mononuclear and dinuclear double-helical silver(I)2,2':6', $2^{\prime \prime}$-terpyridine complexes Chem. Commun. 2659; (b) Ruttimann S, Piguet C, Bernardinelli G, Bocquet B and Williams A F 1992 Self-assembly of dinuclear helical and nonhelical complexes with copper(I) J. Am. Chem. Soc. 114 4230; (c) Shankar B, Sahu S, Deibel N, Schweinfurth D, Sarkar B, Elumalai P, Gupta D, Hussain F, Krishnamoorthy G and Sathiyendiran M 2014 Luminescent dirhenium(I)-double-heterostranded helicate and mesocate Inorg. Chem. 53922

13. Khutia A, Miguel P J and Lippert B 2011 Directed assembly of metallacalix[n] arenes with pyrimidine nucleobase ligands of low symmetry: interchanging metals in mixedmetal metallacalix [4] arenes and incorporating additional metals at the exocyclic groups Chem. Eur. J. 174205

14. Hannon M J, Painting C L and Alcock N W 1999 A metallo-supramolecular double-helix containing a major and a minor groove Chem. Commun. 2023

15. Cooke D J, Cross J M, Fennessy R V, Harding L P, Rice C R and Slater C 2013 Steric control of the formation of dinuclear double helicate and dinuclear meso-helicate assemblies Chem. Commun. 497785

16. Guchhait T, Barua B, Biswas A, Basak B and Mani G 2015 Synthesis and structural characterization of silver(I), copper(I) coordination polymers and a helicate palladium(II) complex of dipyrrolylmethane-based dipyrazole ligands: The effect of meso substituents on structural formation Dalton Trans. 449091

17. Telfer S G, Sato T and Kuroda R 2004 Noncovalent ligand strands for transition-metal helicates: The straightforward and stereoselective self-assembly of dinuclear double-stranded helicates using hydrogen bonding Angew. Chem. 116591

18. Katagiri H, Miyagawa T, Furusho Y and Yashima E 2006 Synthesis and optical resolution of a double helicate consisting of ortho-linked hexaphenol strands bridged by spiroborates Angew. Chem. 1181773

19. Dömer J, Slootweg J C, Hupka F, Lammertsma K and Hahn F E 2010 Subcomponent assembly and transmetalation of dinuclear helicates Angew. Chem. Int. Ed. 49 6430

20. (a) Naranthatta M C, Bandi S, Jagan R and Chand D K 2016 Double-stranded binuclear helicates and helicity modulation Cryst. Growth Des. 16 6722; (b) Krishnaswamy and Chand D K 2017cis-Protected palladium(II) based binuclear complexes as tectons in crystal engineering and the imperative role of the cis-protecting agent CrystEngComm 195157

21. (a) Shaul M and Cohen Y 1999 Novel phenanthrolinecontaining trinuclear double-stranded helicates: Selfrecognition between helicates with phenanthroline and bipyridine binding sites J. Org. Chem. 64 9358; (b) Baker A T, Craig D C and Dong G 1996 A trinuclear doublehelical metal complex of a quinquepyridine analog Inorg. Chem. 35 1091; (c) Hasenknopf B and Lehn J M 1996 Trinuclear double helicates of iron(II) and nickel(II): 
Self-assembly and resolution into helical enantiomers HeIv. Chim. Acta 791643

22. (a) Thuéry P and Harrowfield J 2015 A new form of triple-stranded helicate found in uranyl complexes of aliphatic $\alpha$, $\omega$-dicarboxylates Inorg. Chem. 54 10539; (b) Xu J, Parac T N and Raymond K N 1999 meso myths: what drives assembly of helical versus meso$\left[\mathrm{M}_{2} \mathrm{~L}_{3}\right]$ clusters? Angew. Chem. Int. Ed. 38 2878; (c) Yeh R M and Raymond K N 2006 Supramolecular asymmetric induction in dinuclear triple-stranded helicates Inorg. Chem. 451130

23. Roberts D A, Castilla A M, Ronson T K and Nitschke J R 2014 Post-assembly modification of kinetically metastable $\mathrm{Fe}^{\mathrm{II}}{ }_{2} \mathrm{~L}_{3}$ triple helicates J. Am. Chem. Soc. 1368201

24. Gütz C, Hovorka R, Struch N, Bunzen J, Meyer-Eppler G, Qu Z -W, Grimme S, Topic F, Rissanen K, Cetina M, Engeser M and Lützen A 2014 Enantiomerically pure trinuclear helicates via diastereoselective self-assembly and characterization of their redox chemistry J. Am. Chem. Soc. 13611830

25. Akhuli B, Cera L, Jana B, Saha S, Schalley C A and Ghosh P 2015 Formation and transmetalation mechanisms of homo and heterometallic $(\mathrm{Fe} / \mathrm{Zn})$ trinuclear triple-stranded side-by-side helicates Inorg. Chem. 54 4231

26. Bodman S E and Fitchett C M 2014 Conformational control of the self-assembly of triple helicates and $[2 \times$ 2]-grids from zinc(II) and 3,6-di(2-pyridyl)pyridazine based ligands Dalton Trans. 4312606

27. (a) Chen $Y-H$, Lee $C-C$, Wang C -C, Lee $\mathrm{G}-\mathrm{H}$, Lai S -Y, Li F-Y, Mou C -Y and Peng S -M 1999 A linear metal string $\left[\mathrm{Cr}_{7}\left(\mu_{7} \text {-teptra }\right)_{4} \mathrm{Cl}_{2}\right]$ complex with delocalized heptachromium(II) multiple bonds (teptraH3 = tetrapyridyltriamine) Chem. Commun. 1667; (b) Pan F, Wu J, Hou H and Fan Y 2010 Solvent-mediated central metals transformation from a tetranuclear $\mathrm{Ni}^{\mathrm{II}}$ cage to a decanuclear Cu ${ }^{\mathrm{II}}$ "pocket" Cryst. Growth Des. 10 3835; (c) Baxter P N W, Lehn J M, Baum G and Fenske D 2000 Self-assembly and structure of interconverting multinuclear inorganic arrays: $\mathrm{A}[4 \times 5]-\mathrm{Ag}_{20}^{I}$ grid and $\mathrm{Ag}_{10}^{I}$ quadruple helicate Chem. Eur. J. 6 4510; (d) Boer S A and Turner D R 2015 Self-selecting homochiral quadruple-stranded helicates and control of supramolecular chirality Chem. Commun. 5117375

28. (a) McMorran D A and Steel P J 1998 The first coordinatively saturated, quadruply stranded helicate and its encapsulation of a hexafluorophosphate anion Angew. Chem. Int. Ed. Engl. 37 3295; (b) McNeill S M, Preston D, Lewis J E M, Robert A, Knerr-Rupp K, Graham D O, Wright J R, Giles G I and Crowley J D 2015 Biologically active $\left[\mathrm{Pd}_{2} \mathrm{~L}_{4}\right]^{4+}$ quadruply-stranded helicates: stability and cytotoxicity Dalton Trans. 44 11129; (c) Zhou L -P and Sun Q -F 2015 A self-assembled $\mathrm{Pd}_{2} \mathrm{~L}_{4}$ cage that selectively encapsulates nitrate Chem. Commun. 51 16767; (d) Scott S Ø, Gavey E L, Lind S J, Gordon K C and Crowley J D 2011 Self-assembled palladium(II) "click" cages: synthesis, structural modification and stability Dalton Trans. 40 12117; (e) Clever G H and Punt P 2017 Cation-anion arrangement patterns in self-assembled $\mathrm{Pd}_{2} \mathrm{~L}_{4}$ and $\mathrm{Pd}_{4} \mathrm{~L}_{8}$ coordination cages Acc. Chem. Res. 502233
29. Fukuda M, Sekiya R and Kuroda R 2008 A quadruply stranded metallohelicate and its spontaneous dimerization into an interlocked metallohelicate Angew. Chem. Int. Ed. 47706

30. Kishi N, Li Z, Yoza K, Akita M and Yoshizawa M 2011 An $\mathrm{M}_{2} \mathrm{~L}_{4}$ molecular capsule with an anthracene shell: Encapsulation of large guests up to $1 \mathrm{~nm} \mathrm{J.} \mathrm{Am.} \mathrm{Chem.}$ Soc. 13311438

31. Crowley J D and Gavey E L 2010 Use of di1,4-substituted-1,2,3-triazole "click" ligands to self-assemble dipalladium(II) coordinatively saturated, quadruply-stranded helicate cages Dalton Trans. 394035

32. (a) Faulkner R A, Harding L P, Higginson J, Rice C R and Slater C 2014 Formation of a dimer of trinuclear helicates which encapsulates an array of six hydrogen-bonded anions Angew. Chem. Int. Ed. 53 13540; (b) Hamblin J, Tuna F, Bunce S, Childs L J, Jackson A, Errington W, Alcock N W, Nierengarten H, Dorsselaer A V, LeizeWagner E and Hannon M J 2007 Supramolecular circular helicates formed by destabilisation of supramolecular dimers Chem. Eur. J. 13 9286; (c) Childs L J, Alcock N W and Hannon M J 2002 Assembly of a nanoscale chiral ball through supramolecular aggregation of bowl-shaped triangular helicates Angew. Chem. Int. Ed. 41 4244; (d) Baudron S A, Ruffin H and Hosseini M W 2015 On Zn(II) 2,2'-bisdipyrrin circular helicates Chem. Commun. 51 5906; (e) Lin S - Y, Zhao L, Guo Y N, Zhang P, Guo Y and Tang J 2012 Two new $\mathrm{Dy}_{3}$ triangles with trinuclear circular helicates and their single-molecule magnet behavior Inorg. Chem. 51 10522; (f) Wu Z, Chen Q, Xiong S, Xin B, Zhao Z, Jiang L and Ma J S 2003 Double-stranded helicates, triangles, and squares formed by the selfassembly of pyrrol-2-ylmethyleneamines and $\mathrm{Zn}^{\mathrm{II}}$ ions Angew. Chem. Int. Ed. 42 3271; (g) Mamula O, Lama M, Telfer S G, Nakamura A, Kuroda R, Stoeckli-Evans $\mathrm{H}$ and Scopelitti R 2005 A trinuclear Eu ${ }^{\mathrm{III}}$ array within a diastereoselectively self-assembled helix formed by chiral bipyridine-carboxylate ligands Angew. Chem. Int. Ed. 44 2527; (h) Hasenknopf B, Lehn J -M, Kneisel B O, Baum G and Fenske D 1996 Self-assembly of a circular double helicate Angew. Chem. Int. Ed. Engl. 35 1838

33. Baum G, Constable E C, Fenske D, Housecroft C E and Kulke T 1999 Chiral 1,2-ethanediyl-spaced quaterpyridines give a library of cyclic and double helicates with copper(I) Chem. Commun. 195

34. Wu Z -S, Hsu J -T, Hsieh C -C and Horng Y -C 2012 Assembly and disassembly of a $\mathrm{Zn}_{10}$ high-nuclearity circular helicate Chem. Commun. 483436

35. Mobian P, Baradel N, Kyritsakas N, Khalil G and Henry M M 2015 A bowl-shaped circular trinuclear helicate generated from a $\mathrm{TiO}_{4} \mathrm{~N}_{2}$ motif by a multicomponent self-assembly approach Chem. Eur. J. 21 2435

36. Panneerselvam A P, Jagan R and Chand D K 2017 Trinuclear Intro-vertere circular helicate and its columnar hexagonal packing Cryst. Growth Des. 172929

37. Albrecht M, Janser I, Houjou H and Fröhlich R 2004 Long-range stereocontrol in the self-assembly of twonanometer-dimensioned triple-stranded dinuclear helicates Chem. Eur. J. 102839 